\title{
WldS and PGC- $1 \alpha$ Regulate Mitochondrial Transport and Oxidation State after Axonal Injury
}

\author{
Kelley C. 0'Donnell, ${ }^{1}$ Mauricio E. Vargas, ${ }^{1,2}$ and Alvaro Sagasti ${ }^{1}$ \\ ${ }^{1}$ Department of Molecular, Cell and Developmental Biology, and ${ }^{2} J u l e s$ Stein Eye Institute and Department of Ophthalmology, University of California Los \\ Angeles, Los Angeles, California 90095
}

\begin{abstract}
Mitochondria carry out many of the processes implicated in maintaining axon health or causing axon degeneration, including ATP and reactive oxygen species (ROS) generation, as well as calcium buffering and protease activation. Defects in mitochondrial function and transport are common in axon degeneration, but how changes in specific mitochondrial properties relate to degeneration is not well understood. Using cutaneous sensory neurons of living larval zebrafish as a model, we examined the role of mitochondria in axon degeneration by monitoring mitochondrial morphology, transport, and redox state before and after laser axotomy. Mitochondrial transport terminated locally after injury in wild-type axons, an effect that was moderately attenuated by expressing the axon-protective fusion protein Wallerian degeneration slow (WldS). However, mitochondrial transport arrest eventually occurred in WldS-protected axons, indicating that later in the lag phase, mitochondrial transport is not required for axon protection. By contrast, the redox-sensitive biosensor roGFP2 was rapidly oxidized in the mitochondrial matrix after injury, and WldS expression prevented this effect, suggesting that stabilization of ROS production may mediate axon protection. Overexpression of PGC- $1 \alpha$, a transcriptional coactivator with roles in both mitochondrial biogenesis and ROS detoxification, dramatically increased mitochondrial density, attenuated roGFP2 oxidation, and delayed Wallerian degeneration. Collectively, these results indicate that mitochondrial oxidation state is a more reliable indicator of axon vulnerability to degeneration than mitochondrial motility.
\end{abstract}

\section{Introduction}

Axons are vulnerable to changes in energy production, organelle transport, and oxidative stress, all of which accompany axon degeneration (Coleman, 2005). The relative importance of each of these processes in degeneration has been difficult to parse, given their interdependence and the challenge of monitoring them in vivo. Mitochondria perform many of the processes implicated in degeneration, including ATP and reactive oxygen species (ROS) generation, as well as calcium buffering and protease activation. Therefore, it is not surprising that changes in mitochondrial function and transport are frequently observed during axon degeneration (Court and Coleman, 2012); however, the specific role that mitochondria play in these processes remains poorly understood.

Mitochondria have been linked to Wallerian degeneration (WD), a stereotyped program by which injured axons degenerate that shares features with axon pathology in neurodegenerative diseases (Coleman, 2005). Recent studies suggest that mitochon-

\footnotetext{
Received March 28, 2013; revised Aug. 5, 2013; accepted Aug. 7, 2013.

Author contributions: K.C.O., M.E.V., and A.S. designed research; K.C.O. and M.E.V. performed research; K.C.O. and A.S. analyzed data; K.C.O. and A.S. wrote the paper.

K.C.O. was supported by a training grant from the UCLA Training Program in Neural Repair (NINDS T32 NS07449: 13). M.E.V. was supported by the Jules Stein EyeSTAR Training Program. This work was supported by grants to A.S. from the National Institutes of Dental and Craniofacial Research (R01 DE018496), and the American Parkinson Disease Association Pilot Fund (20082501). We thank Meghan Johnson and Carla Koehler for the mitoDsRed and mito-roGFP constructs and Jeffrey Rasmussen for comments on the paper.

Correspondence should be addressed to Dr Alvaro Sagasti, University of California Los Angeles, 621 Charles East Young Drive South, Los Angeles, CA 90095. E-mail: sagasti@mcdb.ucla.edu.

DOI:10.1523/JNEUROSCI.1331-13.2013

Copyright $\odot 2013$ the authors $\quad 0270-6474 / 13 / 3314778-13 \$ 15.00 / 0$
}

dria may directly initiate WD, potentially through activation of the mitochondrial permeability transition pore (mPTP; Barrientos et al., 2011). WD can be dramatically delayed by the Wallerian degeneration slow protein (WldS), a mutant mouse protein created by a spontaneous genomic rearrangement (Perry et al., 1991; Coleman et al., 1998; Mack et al., 2001). Recent evidence suggests that the protective effects of WldS are mediated by mitochondria (Avery et al., 2012; Fang et al., 2012). For example, mitochondria isolated from WldS-expressing axons exhibit increased ATP production (Yahata et al., 2009) and calcium buffering (Avery et al., 2012), and a recent study found a correlation between mitochondrial transport and axon protection by WldS (Avery et al., 2012). However, whether mitochondrial transport is necessary or sufficient for axon protection after injury is not clear. Moreover, conflicting data indicate that mitochondria can either promote or inhibit axon degeneration in different contexts (Fang et al., 2012; Kitay et al., 2013).

To examine the role of mitochondria in axon degeneration we have imaged them in zebrafish peripheral sensory neurons undergoing WD. This model can be used to monitor the entire process of WD in vivo (O'Brien et al., 2009a; Martin et al., 2010) and to characterize dynamic subcellular events (Plucińska et al., 2012). By imaging mitochondria after axotomy in these neurons, we have characterized mitochondrial density, morphology, transport, and redox state during WD. Axonal injury led to mitochondrial transport arrest and oxidation of the redox-sensitive biosensor roGFP2 (Hanson et al., 2004) in the mitochondrial matrix, suggesting that mitochondrial ROS production may be relevant to axon degeneration. Increased mitochondrial transport 
A
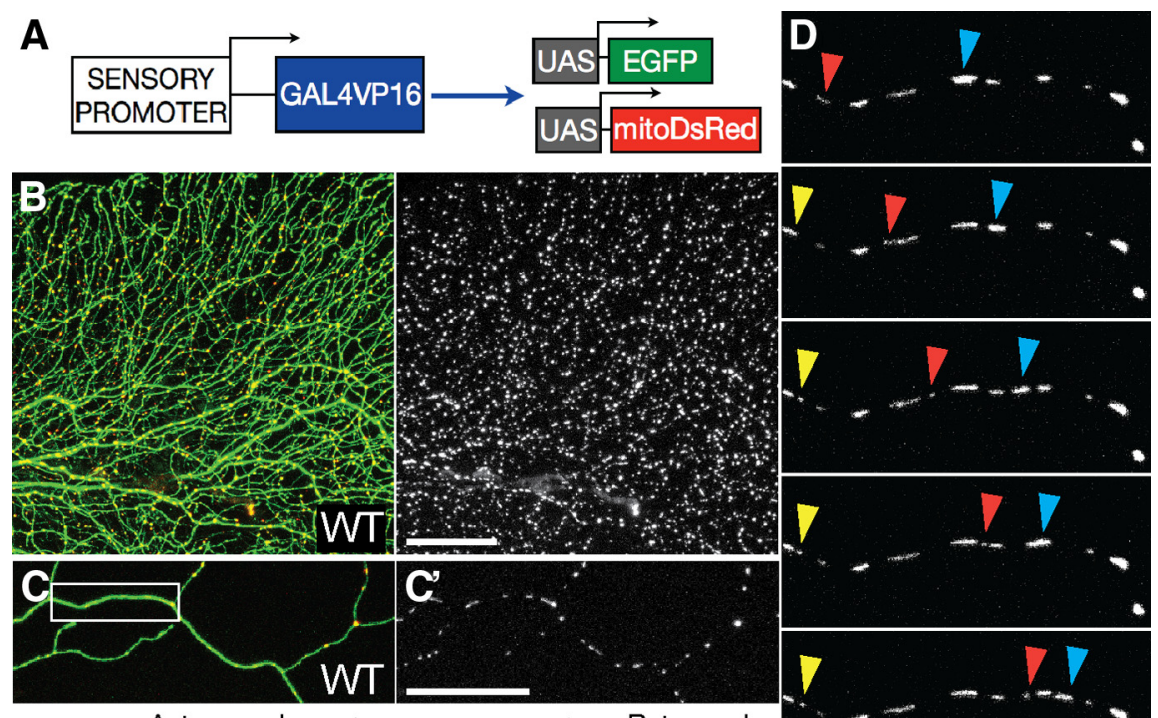

E

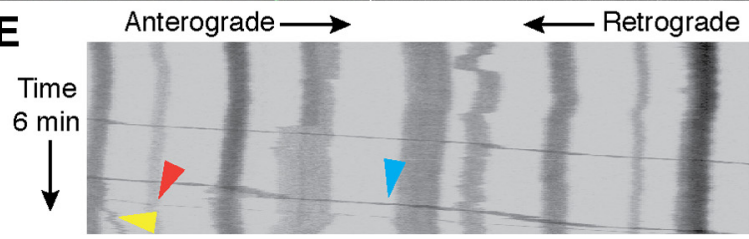

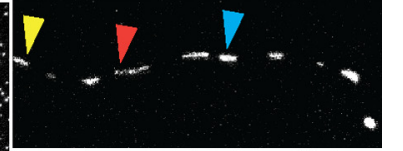
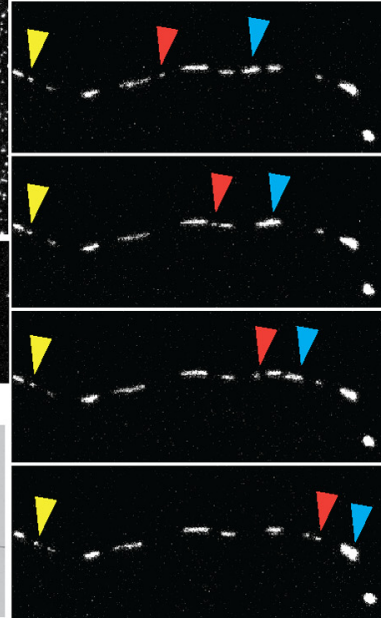

Figure 1. In vivo imaging of mitochondrial transport in zebrafish somatosensory neurons. $\boldsymbol{A}$, Transgenes to visualize GFP in neurons and DsRed in the mitochondrial matrix. $\boldsymbol{B}$. When a stable UAS-mitoDsRed transgenic fish line was crossed to a previously described line in which the is/1(ss) sensory promoter drives Gal4 and GFP expression in somatosensory neurons, red fluorescent mitochondria $\left(\boldsymbol{B}^{\prime}\right)$ were visible in green fluorescent axons. $\boldsymbol{C}, \boldsymbol{C}^{\prime}$, To permit quantification of mitochondrial transport in a single cell, the CREST3:Gal4-UAS-GFP reporter transgene was injected into UAS-mitoDsRed embryos at the one-cell stage for transient mosaic gene expression. $\boldsymbol{D}$, A single optical section was repeatedly imaged at a frequency of $1 \mathrm{~Hz}$ to quantify mitochondrial motility (the percentage of mitochondria that moved within a 6 min movie), and to characterize transport speed and direction. Images in $\boldsymbol{D}$ represent still frames every $1 \mathrm{~min}$. $\boldsymbol{E}$, Kymograph representing transport in a representative axon. Arrows point to moving mitochondria in $\boldsymbol{D}$. Scale bars, $50 \mu \mathrm{m}$. White box in $\boldsymbol{C}$ represents axonal segment in $\boldsymbol{D}$.

was neither necessary nor sufficient for axon protection. By contrast, expression of WldS or the transcriptional coactivator PGC- $1 \alpha$ prevented roGFP2 oxidation and delayed axon degeneration. Collectively, our results suggest that stabilization of mitochondrial redox state may regulate axon protection after injury.

\section{Materials and Methods}

Animal care

Fish were raised on a $14 / 10 \mathrm{~h}$ light/dark cycle at $28.5^{\circ} \mathrm{C}$. Embryos were maintained in a $28.5^{\circ} \mathrm{C}$ incubator. Experiments were performed at larval stages, when male and female zebrafish cannot be distinguished. All experiments were approved by the Chancellor's Animal Research Care Committee at the University of California, Los Angeles.

\section{Injections}

For transient, mosaic gene expression in sensory neurons, $\sim 10$ pg of each transgene was injected at the one-cell stage into wild-type $\mathrm{AB}$ or nacre (Lister et al., 1999) embryos or embryos from the transgenic lines described below. Embryos were screened for fluorescent transgene expression in Rohon-Beard (RB) neurons at $24-48 \mathrm{~h}$ postfertilization (hpf), using a Zeiss Discovery.V12 SteREO fluorescence dissecting microscope.

\section{Transgenes}

The stable transgenic lines used to visualize sensory neurons have been described previously (Sagasti et al., 2005; Palanca et al., 2013). Briefly, the isl1(ss) enhancer from the islet-1 gene (Higashijima et al., 2000) was used to drive expression of Gal4VP16, which activated expression of EGFP or DsRed under control of the Gal4 upstream activation sequence (14 copies, 14XUAS; Köster and Fraser, 2001). For studies of mitochondrial transport after injury, fish from a previously described stable transgenic line expressing GFP under the

control of the Fru.trkA enhancer (Palanca et al., 2013) were also used, because their reporter expression was sparse, allowing the identification of embryos expressing GFP in a single RB neuron. For developmental experiments in wild-type embryos, sensory neurons were visualized by transient injection of the isl1(ss):Gal4VP16-14XUAS, reporter plasmids used to generate the stable lines described above. The Tol2/Gateway zebrafish kit (Kwan et al., 2007) was used for construction of all remaining plasmids. In all cases transgene expression was driven by the CREST3 enhancer (gift from Hitoshi Okomoto, RIKEN Brain Science Institute, Tokyo, Japan; Uemura et al., 2005). Like isll(ss), the CREST3 enhancer is derived from the islet-1 gene and drives expression in peripheral sensory neurons.

WldS. For coexpressing GFP and WldS in sensory neurons, we used a previously described transgene (CREST3:Gal4VP1614xUAS-GFP-14xUAS-WldS; Martin et al., 2010). To achieve equimolar expression of DsRed and WldS, we used the viral T2A sequence, which causes ribosomal skipping (Donnelly et al., 2001; Tang et al., 2009). This sequence was inserted into the Gateway system (Invitrogen) behind a multiple cloning site. WldS was amplified using primers to add XhoI and HindIII restriction sites to the $5^{\prime}$ and the $3^{\prime}$ ends of the sequence, respectively, and cloned into the system to generate CREST3: Gal4VP16-14XUAS-WldS-2A-DsRed.

$P G C-1 \alpha$. A plasmid encoding mouse PGC$1 \alpha$, which was previously expressed in zebrafish (Hanai et al., 2007), was a gift from Shintaro Imamura (National Research Institute of Fisheries Science, Yokohama, Japan). The PGC- $1 \alpha$ coding sequence was amplified using primers to add XhoI and BamHI to the $5^{\prime}$ and $3^{\prime}$ ends of the sequence, respectively. The sequence and the p3E-MCS-2A-DsRed and p3E-MCS-2A-GFP Gateway donor vectors were cloned with $\mathrm{XhoI}$ and $\mathrm{BamHI}$ sites to generate $\mathrm{p} 3 \mathrm{E}-$ PGC- $1 \alpha-2 \mathrm{~A}-\mathrm{DsRed}$ and $\mathrm{p} 3 \mathrm{E}-\mathrm{PGC}-1 \alpha-2 \mathrm{~A}-\mathrm{GFP}$. These donor vectors were then recombined to generate CREST3:Gal4VP16-14XUAS-PGC$1 \alpha$-2A-GFP and CREST3:Gal4VP16-14XUAS-PGC- $1 \alpha-2 A-D s R e d$.

MitoDsRed. To visualize mitochondria, a cox 8 mitochondrial targeting sequence was added to DsRed (mitoDsRed; gift from Meghan Johnson and Carla Koehler, UCLA, Los Angeles, CA). The reporter UAS-mitoDsRed-polyA was used to generate a MitoDsRed transgenic line using the Tol2 system (Kawakami, 2004). The plasmid, which contained Tol2 sites flanking UAS-mitoDsRed-polyA, was injected with transposase mRNA into zebrafish eggs at the one cell stage. These fish were raised and crossed to isl1(ss):Gal4VP16:14XUAS-GFP fish. Progeny from this cross were then screened for the expression of GFP and mitoDsRed in sensory neurons. These double-transgenic fish were then crossed to wild-type AB fish to obtain a line of single-transgenic UAS-mitoDsRed fish.

Mito-roGFP2. To monitor changes in the mitochondrial redox potential, roGFP2 (Hanson et al., 2004) was localized to the mitochondrial matrix with a cox 8 targeting sequence (mito-roGFP2; gift from Meghan Johnson and Carla Koehler). Mito-roGFP2 was cloned into the Gateway system to generate UAS-mito-roGFP2-polyA. This transgene was coinjected with one of the CREST3:DsRed reporters described above, for expression of DsRed ( \pm WldS or PGC- $1 \alpha$ ) in the axon and mito-roGFP2 in the mitochondrial matrix.

Synaptophysin-GFP. The transgene encoding the zebrafish synaptophysin-EGFP fusion protein (Syp-GFP) has been described (Meyer and Smith, 2006), and was a gift from Martin Meyer (King's College, London, UK). 

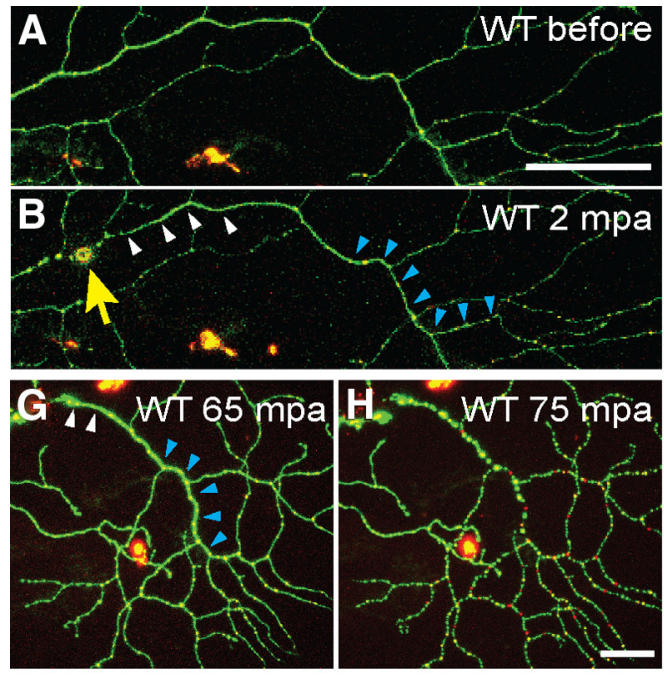

I
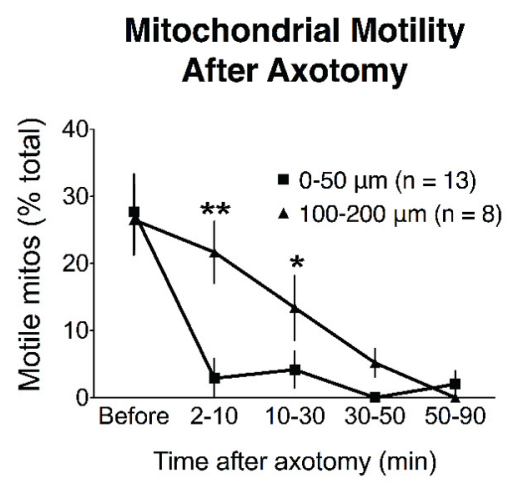

Figure 2. Axonal injury causes mitochondrial transport arrest in a separated axon fragment. $\boldsymbol{A}, \boldsymbol{B}$, Mitochondrial transport was imaged in a $50 \mu \mathrm{m}$ axon segment before $(\boldsymbol{A})$ and after $(\boldsymbol{B}) \mathrm{GFP}$ - and mitoDsRed-expressing axons were severed with a laser (yellow arrow points to injury site). Transport was monitored either immediately distal to the injury (white arrowheads) or $100-200 \mu m$ distal (blue arrowheads). $\boldsymbol{C}-\boldsymbol{F}$, Representative kymographs from $50 \mu \mathrm{m}$ axonal segments before and after axotomy at the two locations. Red arrowhead in $\boldsymbol{F}$ points to motile mitochondrion in more distal region 20 min post-axotomy (mpa). $\mathbf{G}, \boldsymbol{H}$, The distal axon ultimately fragmented synchronously: the entire detached axon was intact $65 \mathrm{mpa}(\boldsymbol{G})$, and had fragmented by $75 \mathrm{mpa}(\boldsymbol{H}) . \boldsymbol{I}$, Quantification of mitochondrial motility before and at various time points after axotomy. Adjacent to the injury, motility stopped abruptly (percentage motile before: $27.00 \pm 4.35 \% ; 2-10$ mpa: $4.50 \pm 2.64 \% ; n=13$ axons, $p=0.0001)$ and did not recover (10-90 mpa: $2.70 \pm 0.86 \% ; p<0.0001)$. Further from the injury (100-200 $\mu \mathrm{m})$, mitochondrial transport did not immediately terminate (percentage motile before: $26.51 \pm 5.25 \%$ motile; $2-10 \mathrm{mpa}: 21.68 \pm 4.57, n \geq 8$ axons; $p=0.5386$ ); however, the characteristics of transport were acutely affected $(\boldsymbol{J}, \boldsymbol{K}$ ). $\boldsymbol{J}$, At the $100-200 \mu \mathrm{m}$ distal site, motile mitochondria spent a higher percentage of time paused immediately after axotomy (before: $43.28 \pm 7.91 \% ; 2-10 \mathrm{mpa}: 74.48 \pm 7.73 \%$ ), and proportionally less time moving in the anterograde direction, away from the cut site (before: $39.45 \pm 7.96 \% ; 2-10 \mathrm{mpa}: 8.55 \pm 3.71 \%, n \geq 21$ mitochondria from $\geq 9$ axons, $p<0.001$ ). By $10-30 \mathrm{mpa}$, however, this difference was no longer significant (Bonferroni post-test, $p>0.05$ ). $\boldsymbol{K}$, Quantification of the speed of uninterrupted runs (not counting time paused) revealed that retrograde transport was reduced acutely in mitochondria after injury (retrograde speed before: $0.67 \pm 0.09 \mu \mathrm{m} / \mathrm{s} ; 2-10 \mathrm{mpa}: 0.36 \pm 0.06 \mu \mathrm{m} / \mathrm{s} ; n \geq 8 \mathrm{mitochondria}$ from $\geq 5$ axons, $p=0.0286$ ), but anterograde speed was not affected (before: $0.46 \pm 0.05 \mu \mathrm{m} / \mathrm{s} ; 2-10 \mathrm{mpa}: 0.40 \pm 0.04 \mu \mathrm{m} / \mathrm{s} ; n \geq 8$ mitochondria from $\geq 5$ axons). Later in the lag phase, retrograde transport velocity recovered (10-30 mpa: $0.51 \pm 0.08 \mu \mathrm{m} / \mathrm{s} ; p=0.238)$. Despite this transient recovery, transport eventually stopped throughout the distal axon $(I)$ before fragmentation. Scale bars, $50 \mu \mathrm{m}$.

\section{Morpholinos}

Morpholino oligonucleotides targeting the zebrafish pink1 gene (NM_001008628; Anichtchik et al., 2008) were acquired from GeneTools. Sequences were as previously described (ATG targeting, $5^{\prime}$-GCT GAG AAC ATG CTT TAC TGA CAT T-3'; $5^{\prime}$-untranslated region targeting, 5'-ATA TTG ACT ATG AGA GGA AAT CTG A-3') and 7 ng of each morpholino were coinjected into one-cell stage embryos (Anichtchik et al., 2008), in combination with the plasmids described above. Control embryos were injected with $14 \mathrm{ng}$ of the standard GeneTools control morpholino (5'-CCT CTT ACC TCA GTT ACA ATT TAT A-3').

\section{Imaging axons and mitochondria}

Embryos were dechorionated, anesthetized in $0.01-0.02 \%$ tricaine, mounted in $1.2 \%$ low-melt agarose (Promega, V2111) in sealed chambers (O'Brien et al., 2009b), and imaged on a heated stage kept at $28.5^{\circ} \mathrm{C}$. For time-lapse analysis of mitochondrial movement and WD, GFP-, and mitoDsRed-expressing embryos were imaged at various intervals for up to $3 \mathrm{~h}$ on a confocal microscope (Zeiss LSM 510).
Images were compiled into projections and movies with QuickTime software.

Mitochondrial imaging. To monitor mitochondrial morphology and density, GFP reporter transgenes were injected into UAS-mitoDsRedexpressing embryos. Embryos were imaged at $2-4 \mathrm{~d}$ post-fertilization (dpf) using a confocal microscope with a $40 \times$ oil objective and $3 \times$ digital zoom. Mitochondrial and vesicular transport imaging was limited to a single optical section. Before each time-lapse movie, an image was taken using both 488 and $543 \mathrm{~nm}$ lasers, so that the axon could be visualized for later analysis. Mitochondria or vesicles were imaged every second for $6 \mathrm{~min}$. In the case of axotomy, a time-lapse movie was made before axon transection for comparison. Only axons in which at least one mitochondrion moved before injury were then cut and imaged for postinjury analysis. For evaluation of relative redox potential, mito-roGFP2-expressing embryos were imaged with a $20 \times$ air objective and $4 \times$ digital zoom. Images were taken before and at various intervals after injury, scanning at $543 \mathrm{~nm}$ to visualize red axons, and at 405 and $488 \mathrm{~nm}$ to monitor roGFP2 oxidation. 
A
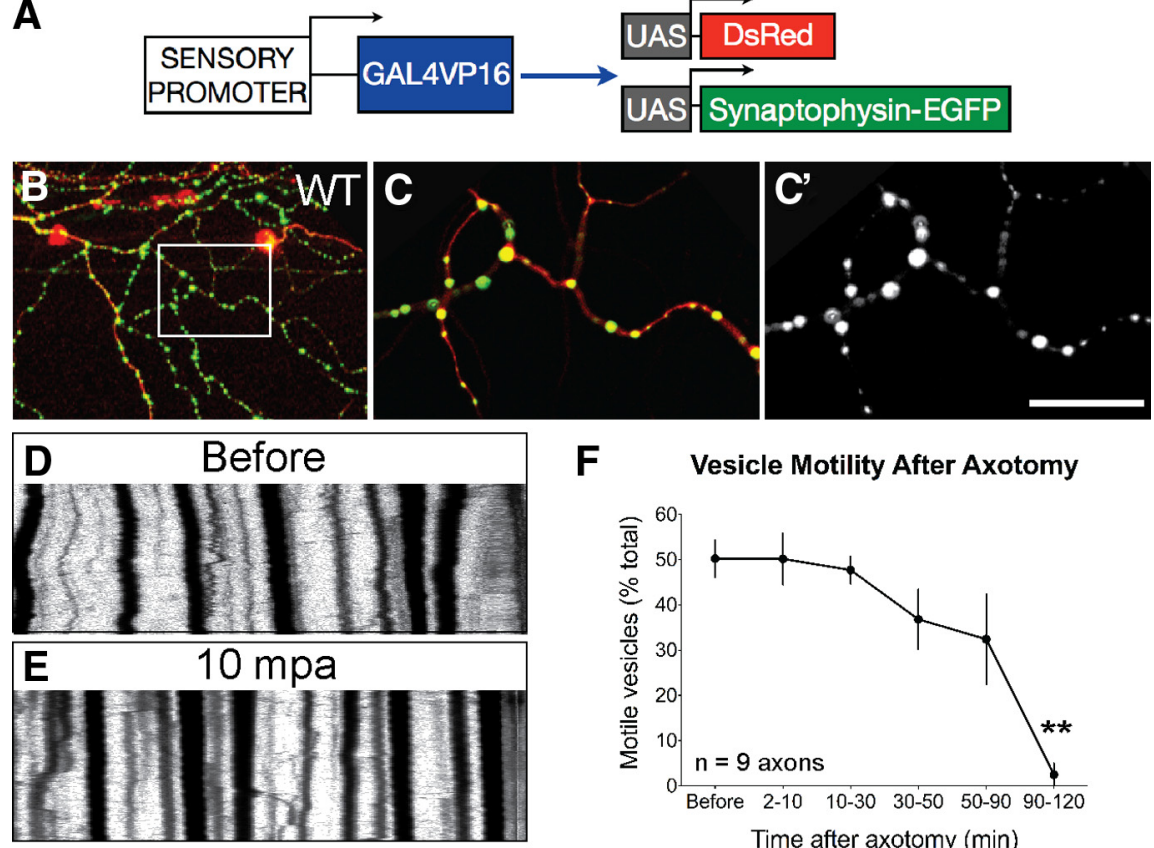

$\mathbf{F}$

Vesicle Motility After Axotomy

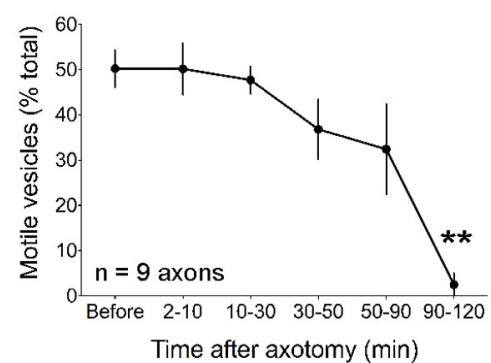

Figure 3. Vesicular transport is not affected by axonal injury. $\boldsymbol{A}-\boldsymbol{C}$, DsRed and a synaptophysin-GFP fusion protein were expressed in axons to visualize vesicle transport before and after axotomy in $2 \mathrm{dpf}$ embryos. Image in $\left(\boldsymbol{C}, \boldsymbol{C}^{\prime}\right)$ is a single optical section taken from boxed region in $\boldsymbol{B}$. $\boldsymbol{D}, \boldsymbol{E}$, Representative kymographs illustrating vesicle motility before and $10 \mathrm{~min}$ postaxotomy. $\boldsymbol{F}$, In contrast to the acute mitochondrial transport arrest, vesicular transport was not acutely affected by injury (percentage motile before: $50.22 \pm 4.14 \% ; 2-10 \mathrm{mpa}: 50.17 \pm 5.70 \% ; n=9$ axons, $p=0.99)$, and persisted at baseline rates until shortly before axon fragmentation ( $90-120 \mathrm{mpa}: 24.54 \pm 6.81 \%, p=0.0014)$. Scale bar, $50 \mu \mathrm{m}$.

\section{Axon transection}

Axons were cut using a Zeiss microscope (LSM 710) equipped with a multiphoton laser (O'Brien et al., 2009b). Embryos were imaged with a $20 \times$ water objective and $488 / 543 \mathrm{~nm}$ laser scanning to identify the axonal region of interest, then 1-5 scans of the multiphoton laser (tuned to 910 $\mathrm{nm}$ for green axons, $850 \mathrm{~nm}$ for red axons) were used to transect an axonal region of interest at $100 \times$ digital zoom.

\section{Data analysis}

Mitochondrial morphology. Morphology was quantified from 2D projections of confocal stacks generated from images taken at $40 \times, 3 \times$ digital zoom. In the green channel, all axons within an image were traced using ImageJ software. Line length was calibrated to convert pixels to distance, and the Measure plugin for ImageJ was used to determine the length and diameter of each mitochondrion in an image. All mitochondria within an image were quantified, and the ratio of length/width was taken as a measure of mitochondrial morphology. Mean morphology was compared with unpaired $t$ tests. To further analyze morphology, GraphPad Prism software was used to divide mitochondria into bins according to their length/width ratio (bin width: 1.0; i.e., all mitochondria with a length/width ratio between 1 and 2 were in Bin 1), and the relative frequency of each bin was determined as a percentage of the total, and represented in a histogram. Note that all discussions of mitochondrial "length" refer to this ratio, to control for any differences in expression levels that might increase or decrease mitoDsRed fluorescence intensity and thereby affect measurement.

Mitochondrial transport. The percentage of total mitochondria that moved in a $50 \mu \mathrm{m}$ axon segment during a 6 min time-lapse movie was quantified using the kymograph macro for ImageJ. Kymograph color was inverted so that mitochondria appeared black. A mitochondrion was considered to be moving only if it traveled at least $2 \mu \mathrm{m}$, at a speed of at least $0.1 \mu \mathrm{m} / \mathrm{s}$, to be consistent with published work (Misgeld et al., 2007). Speed was calculated as the slope of distance $(x)$ over time $(y)$ on the kymograph. Vesicular transport was quantified using the same parameters. For measures of transport after axotomy, data from all axons were binned according to time after injury, and statistical analysis was performed.

Mitochondrial density. Mitochondrial density in axons of wild-type and WldS-expressing embryos, and in control and PTEN-induced putative kinase 1 (PINK1) morphants, was determined by counting all mitochondria (stationary and motile) in a kymograph. In PGC-1 $\alpha$-expressing neurons, mitochondrial distribution was irregular. For this reason, mitochondrial density was determined from still images in multiple regions of the axon, and values therefore primarily represented the density of stationary mitochondria. Mitochondrial density in still images from wild-type axons was evaluated as a control.

Relative redox potential. The excitation maxima of roGFP2 are $\sim 400$ and $\sim 475-490 \mathrm{~nm}$; under reducing conditions, the $475-490 \mathrm{~nm}$ excitation peak dominates, whereas oxidation results in relatively higher excitation at $400 \mathrm{~nm}$ (Hanson et al., 2004). Using confocal images taken before and at various time points after injury, projections were generated to calculate the 405/488 fluorescence ratio of mitochondria in the $\mathrm{Z}$ stack. Measures were taken from all mitochondria within $100 \mu \mathrm{m}$ of the eventual injury site, and values were pooled to generate a mean fluorescence ratio for each axon before injury. All postinjury values for a given axon were calculated as a percentage of the initial. Data from all axons were then binned according to time after injury, and statistical analysis was performed.

Statistical analysis. GraphPad Prism software was used for statistical analysis. Planned, unpaired Student's $t$ tests were used to compare independent groups. A paired $t$ test was used to compare mito-roGFP2 oxidation in individual axons early and late in the lag period before degeneration. One-way ANOVA was used to compare three or more groups, with Dunnett's post-tests used for comparison to the control. Two-way ANOVA was used to evaluate the effect of time and genotype/location on changes in transport and roGFP2 oxidation after injury, followed by Bonferroni post-tests to evaluate significance at each time point.

\section{Results}

Monitoring mitochondria in living zebrafish sensory neurons To study morphology and motility of mitochondria in a live, vertebrate system, we created reporters to label them in zebrafish somatosensory neurons (Fig. 1A). DsRed fused to the cox8 mitochondrial matrix targeting sequence (mitoDsRed) was placed under the control of UAS elements and used to generate a stable transgenic line (UAS:mitoDsRed; Fig. 1B). The CREST3 enhancer element, which drives expression in peripheral sensory neurons (Uemura et al., 2005; Palanca et al., 2013), was used to drive Gal4VP16, and this transgene was injected into mitoDsRed embryos to achieve mosaic expression in small numbers of sensory neurons (Fig. 1C). Mitochondrial density and transport were evaluated at 2 and $4 \mathrm{dpf}$ in $50 \mu \mathrm{m}$ segments of individual peripheral axons. Cells were monitored for $6 \mathrm{~min}$ at one frame per second (Fig. 1D), and transport was quantified using kymograph analysis (Fig. $1 E$ ). Mitochondrial density was slightly but significantly lower at $4 \mathrm{dpf}(2 \mathrm{dpf}$ : $280 \pm 0.24 \mathrm{mitos} / \mathrm{mm} ; 4 \mathrm{dpf}$ : $208 \pm 0.19$ mitos/mm; $n \geq 16$ cells, $p<0.05$ ) but mitochondrial motility, defined as the percentage of mitochondria that moved at any point within a 6 min time-lapse movie, did not differ significantly between 2 and $4 \mathrm{dpf}(2 \mathrm{dpf}: 23.2 \pm 4.0 \% ; 4 \mathrm{dpf}$ : 
$20.1 \pm 5.1 \% ; n \geq 16$ cells, $p=0.59)$. Among motile mitochondria, the speed of uninterrupted runs in the retrograde direction did not change between 2 and 4 $\operatorname{dpf}(2 \mathrm{dpf}: 0.69 \pm 0.06 \mu \mathrm{m} / \mathrm{s} ; 4 \mathrm{dpf}: 0.58 \pm$ $0.06 \mu \mathrm{m} / \mathrm{s} ; n \geq 16$ mitos in $n \geq 11$ cells, $p=0.383$ ); however, anterograde velocity was higher at $4 \mathrm{dpf}(2 \mathrm{dpf}: 0.50 \pm 0.03$ $\mu \mathrm{m} / \mathrm{s} ; 4 \mathrm{dpf}: 0.65 \pm 0.04 \mu \mathrm{m} / \mathrm{s} ; n \geq 51$ mitos in $n \geq 11$ cells, $p=0.003$ ). The mitoDsRed system can thus be used to detect quantitative changes in axonal mitochondria during development, similar to the recently described MitoFish system (Plucińska et al., 2012).

\section{Mitochondrial transport arrest after injury is local and specific}

Recent studies in invertebrate and in vitro systems have suggested that mitochondrial number and transport decrease upon injury (Avery et al., 2012; Fang et al., 2012). To determine whether mitochondrial transport was also affected in a vertebrate system in vivo, we transected peripheral axons of sensory neurons with a laser at $3 \mathrm{dpf}$. At this stage WD in peripheral sensory neurons is highly stereotyped, and fragmentation occurs $\sim 90$ min after axotomy (Martin et al., 2010). MitoDsRed-expressing axons were imaged before (Fig. 2A) and after (Fig. 2B) laser transection. Mitochondrial transport was monitored along $50 \mu \mathrm{m}$ axon segments either immediately adjacent $(0-50 \mu \mathrm{m})$ or 100-200 $\mu \mathrm{m}$ distal to the site of injury. Within 2 min postaxotomy (mpa), mitochondrial transport completely terminated in the axonal segment immediately distal to the site of injury and never recovered (Fig. 2C, D, I). By contrast, transport in axonal segments further from the cut site was not immediately affected (Fig.

$2 E, F, I)$. However, motile mitochondria in this region spent significantly less time moving in the anterograde direction (away from the cut site), and a greater amount of time paused between runs (Fig. $2 J$ ), and the velocity of uninterrupted runs in the retrograde direction was decreased (Fig. $2 K$ ). Thus, although degeneration is synchronous throughout the distal fragment (Fig. 2G,H; Martin et al., 2010), acute transport arrest was limited to the region nearest the site of injury. However, all mitochondrial transport ultimately stopped in the distal axon before fragmentation.

The eventual loss of all distal mitochondrial movement after injury could be caused by a global impairment of axonal transport, or the effect could be specific to mitochondria. To distinguish between these possibilities, we imaged vesicular transport by expressing a synaptophysin-GFP fusion protein (Meyer and Smith, 2006) in DsRed-labeled axons (Fig. 3A-C). In contrast to the acute mitochondrial transport arrest, vesicular transport was unaffected immediately after axotomy, and persisted at baseline rates until shortly before axon fragmentation (Fig. 3D-F). Mito- chondrial transport arrest after axotomy is therefore not likely caused by generalized microtubule breakdown.

\section{Mitochondrial transport in the proximal axon persists after axotomy}

To examine whether mitochondrial transport arrest correlates with axon degeneration, we monitored mitochondrial motility in the proximal portion of the transected axon $(0-50 \mu \mathrm{m}$ proximal to the injury, Fig. $4 A$ ), which remains connected to the cell body and does not degenerate. Overall mitochondrial motility in the proximal axon was not altered at any point after axotomy (Fig. $4 B-E)$. Motile mitochondria did, however, spend a higher percentage of time paused for the first hour after axotomy (Fig. 4F), and the duration and speed of retrograde movement were also reduced (Fig. $4 G$ ). However, the net direction of transport was not significantly different (Fig. $4 H$ ). Together, these changes in the proximal axon stump favored mitochondrial retention near the injury site. One hour later the differences in mitochondrial transport were no longer statistically significant 
A
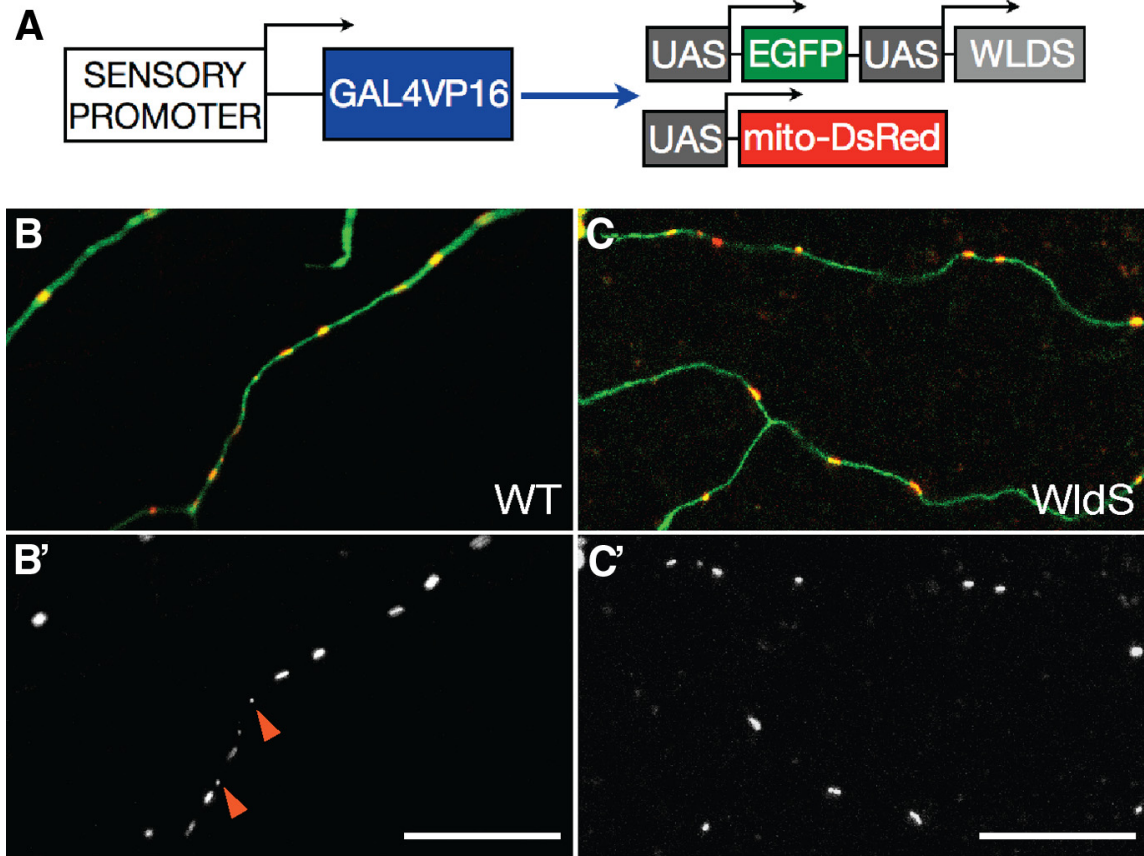

D

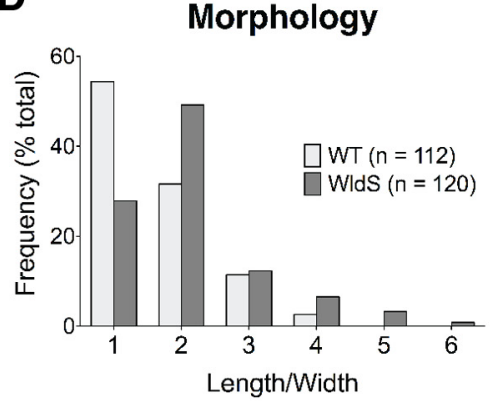

$\mathbf{F}$

Transport Behagviors

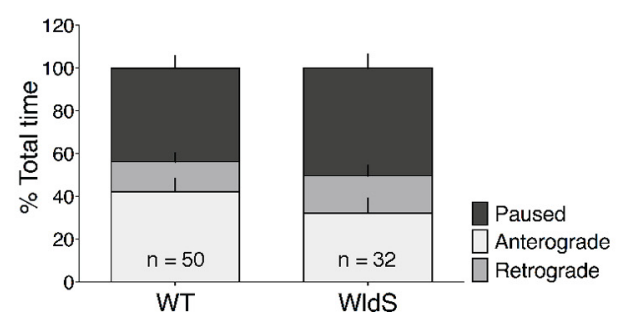

G

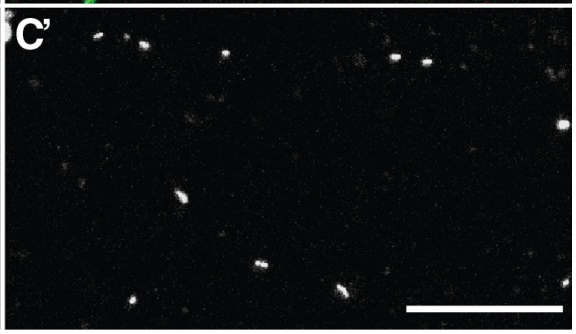

E

Motility

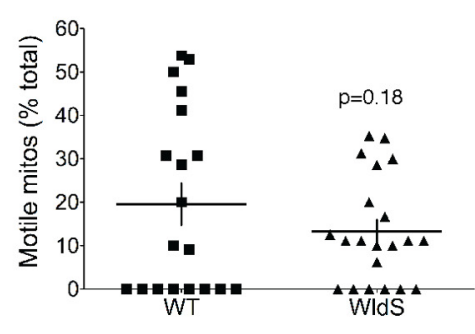

Run Velocity

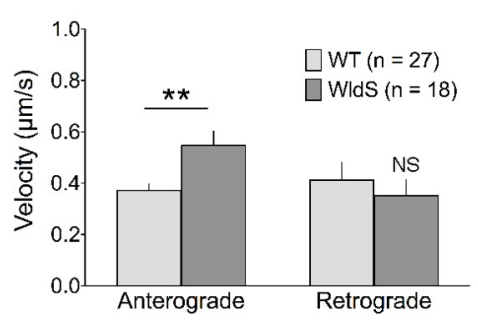

Figure 5. WIdS mildly affects mitochondrial morphology and transport in uninjured axons. $\boldsymbol{A}$, Transgenes used to visualize mitochondria in WIdS-expressing axons. A sensory promoter drove expression of either GFP (WT, $\left.\boldsymbol{B}, \boldsymbol{B}^{\prime}\right)$ or WIdS and GFP $\left(\boldsymbol{C}, \boldsymbol{C}^{\prime}\right)$ in UAS-mitoDsRed embryos. $\boldsymbol{B}-\boldsymbol{D}$, Mitochondria in WIdS-expressing axons were, on average, elongated compared with wild-type mitochondria (WT average length/width ratio: $1.70 \pm 0.07$; WIdS: $2.12 \pm 0.09, p=0.0002$ ). This difference was primarily attributable to the presence of fewer small, spherical mitochondria (length/width ratio of 1 ; WT example indicated by arrowheads in $\boldsymbol{B}^{\prime}$ ), as indicated by the histogram in $\boldsymbol{D}$. $\boldsymbol{E}$, Overall mitochondrial motility in uninjured WIdS-expressing axons was not significantly different from wild-type (WT \% motile: $20.71 \pm 4.96 \%$; WIdS $13.32 \pm 2.66 \% ; n \geq 18$ axons, $p=0.18$ ). $\boldsymbol{F}$, The amount of time motile mitochondria spent paused or moving in either direction was not different from wild-type $(p>0.05)$. G, Mitochondrial transport in the anterograde direction was significantly faster in WIdS-expressing axons (WT anterograde speed: $0.37 \pm 0.03$ $\mu \mathrm{m} / \mathrm{s} ;$ WIds: $0.55 \pm 0.06 \mu \mathrm{m} / \mathrm{s} ; n \geq 18$ mitochondria from $\geq 11$ axons), but retrograde speed was not significantly different (WT: $0.41 \pm 0.07 \mu \mathrm{m} / \mathrm{s} ;$ WldS: $0.35 \pm 0.06 \mu \mathrm{m} / \mathrm{s} ; n \geq 18$ mitochondria from $\geq 11$ axons; $p=0.5282$ ). Scale bar, $20 \mu \mathrm{m}$.

(Fig. 4G). Despite the mild and transient changes in the characteristics of transport, overall mitochondrial motility in the proximal axon was thus preserved after axotomy, supporting the possibility that mitochondrial transport arrest in the distal axon might underlie degeneration.
WldS mildly affects baseline mitochondrial morphology

and transport

Expressing WldS in zebrafish somatosensory axons (Fig. 5) dramatically delays degeneration after transection (Fig. $6 A, B$; Martin et al., 2010). To determine whether WldS alters mitochondrial motility in zebrafish sensory axons we coexpressed WldS and GFP in mitoDsRed-expressing embryos (Fig. 5A-C). Overall mitochondrial density in uninjured WldS-expressing axons did not differ from wild-type axons (WT: $2.20 \pm 0.16 \mathrm{mitos} / \mu \mathrm{m}$; WldS: $2.33 \pm 0.25$ mitos $/ \mu \mathrm{m} ; n \geq 18$ cells, $p=$ 0.64 ), but the average mitochondrial morphology (ratio of length/width) was slightly elongated (Fig. 5B-D). Overall mitochondrial motility in uninjured WldS-expressing axons was not significantly different from wild-type (Fig. 5E). The amount of time motile mitochondria spent either paused or moving in either direction was also not different from wildtype (Fig. $5 F$ ). The speed of anterograde runs was higher in WldS mitochondria than wild-type, but retrograde speed was unchanged (Fig. 5G). Thus, WldS expression in zebrafish somatosensory neurons appears to affect mitochondria only mildly.

WldS modestly and temporarily mitigates mitochondrial transport arrest after axotomy

Although there was no significant difference in baseline mitochondrial motility in WldS-expressing axons, it is possible that preservation of motility after injury underlies its protective effect (Avery et al., 2012). To test this hypothesis, we evaluated mitochondrial transport before and after axotomy. As in wild-type axons, mitochondria in the portion of the axon immediately distal to the injury stopped moving acutely after transection in WldSexpressing axons, but shortly thereafter mitochondrial transport recovered to baseline values (Fig. 6C,D). At that time, motile mitochondria moved more in the retrograde direction than before injury, as measured both by time (Fig. $6 E$ ), and by distance (Fig. 6F). The velocity of uninterrupted runs in either direction was not different (Fig. 6G). Mitochondrial transport during this phase thus favors retrograde movement toward the cut site, similar to the effect seen in the wild-type proximal axon.

The early transport recovery observed in transected WldSexpressing axons was temporary. At all later time points, mitochondrial motility was reduced relative to baseline (Fig. 6D). This observation suggests that long-term protection is not mediated by long-term transport preservation. To further examine this 
idea, we monitored axonal mitochondria in WldS-expressing neurons $24 \mathrm{~h}$ postaxotomy (hpa) and compared mitochondrial motility to uncut axons from age-matched controls. Although distal axons from these WldS-expressing cells were still intact (Fig. 6B), all mitochondria were essentially stationary (4 dpf uncut: $13.71 \pm 3.16 \%$ motile mitochondria; 4 dpf, 24 hpa: $0.45 \pm 0.45 \%$ motile; $14 / 15$ axons had no motile mitos, $p=0.0004$ ). This finding demonstrates that mitochondrial motility is not required for the maintenance of axonal integrity. It also suggests that WldS may not protect axons by regulating mitochondrial transport.

Some studies suggest that uneven mitochondrial distribution induces local hypoxia that initiates axon degeneration (Misko et al., 2012). It is therefore possible that the early attenuation of mitochondrial transport arrest by WldS allows mitochondria to redistribute to a more uniform pattern. To examine this possibility, we first measured mitochondrial distribution in wild-type and WldSexpressing axons before axotomy, and found no difference in average intermitochondrial distance or the variation from the mean (WT before: $4.81 \pm 0.33 \mu \mathrm{m}$; WldS before: $4.36 \pm 0.35 \mu \mathrm{m}, n \geq 73 \mathrm{mi}-$ tos in $\geq 6$ axons, $p=0.370$ ). We then measured mitochondrial spacing between 50 and $90 \mathrm{mpa}$, after the period of transport recovery in WldS had occurred. There was no difference in distribution between wild-type and WldS-expressing cells at that time (WT: $4.53 \pm 0.35 \mu \mathrm{m}$; WldS: $4.73 \pm 0.36 \mu \mathrm{m}, n \geq 68$ mitos in $\geq 6$ axons, $p=0.717)$. These results suggest that WldS does not protect axons by altering mitochondrial distribution after injury.

\section{PINK1 knock-down increases} mitochondrial transport after axotomy without delaying degeneration Observing mitochondria in WldSexpressing axons demonstrated that ongoing motility is not required for protection. To test whether early motility might be sufficient to protect axons from degeneration we sought to prevent their arrest after axotomy with an independent manipulation. Damaged mitochondria accumulate PINK1 on their surface (Matsuda et al., 2010), which ultimately leads to their dissociation from microtubules (Liu et al., 2012). We hypothesized that if transport arrest after axotomy is mediated by PINK1 stabilization on depolarized mitochondria, PINK1 knockdown might promote recovery of transport after transection. We used a previously characterized morpholino (Anichtchik et al., 2008) to knock down PINK1 expression and conducted experiments at 2 dpf to ensure a robust morphant phenotype. We observed the same gross morphological changes previously reported in these morphants, such as cerebral edema (Fig. $7 A, B$ ). Axonal mitochondria
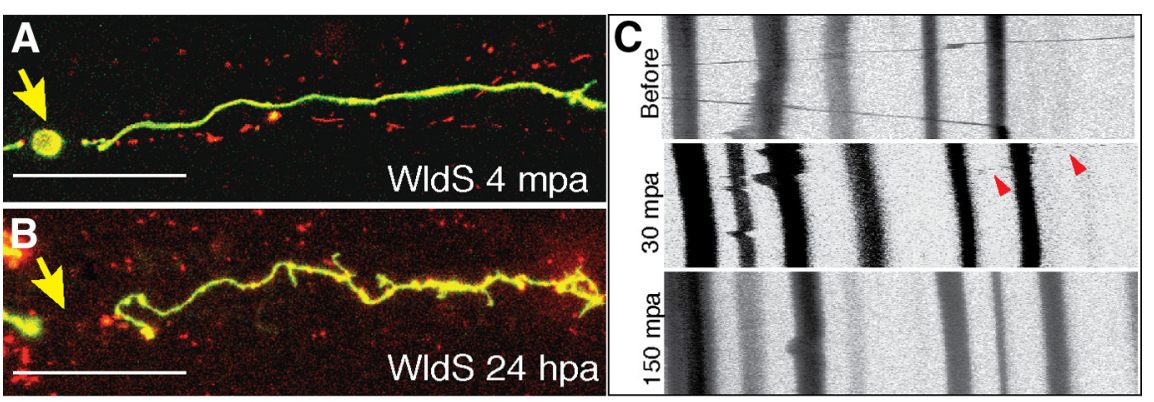

D Mitochondrial Motility

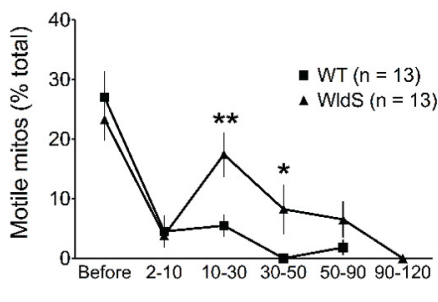

$\mathbf{F}$

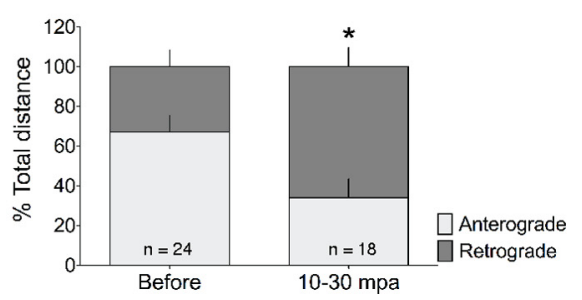

E

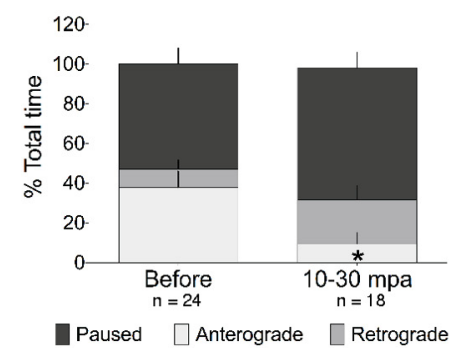

G

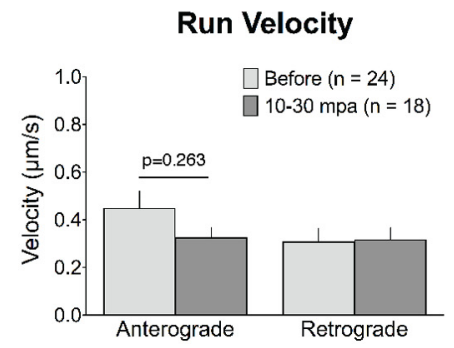

Figure 6. WIdS moderately and temporarily mitigates mitochondrial transport arrest after injury. $\boldsymbol{A}, \boldsymbol{B}$, WIdS-expressing axons were transected and imaged at various time points after injury. $\boldsymbol{B}$, WIdS-expressing axons remained intact $24 \mathrm{hpa}$, despite persistent detachment from the cell body. $\boldsymbol{C}$, Representative kymographs from movies of mitochondrial transport at various time D, As in wild-type axons, acute mitochondrial transport stopped in the distal axon immediately after transection in WIdSthereafter transport temporarily recovered to baseline values (10-30 mpa: $17.43 \pm 3.67 \%, n=13$ cells). Eventually, mitochondrial transport terminated altogether in WIdS-expressing axons (percentage motile 50-90 mpa: $6.53 \pm 2.97 \% ; p=0.0010$ ). Bonferroni post-test). $\boldsymbol{E}$, After recovering from acute transport arrest, motile mitochondria spent a lower percentage of time moving in the anterograde direction than before injury (before: $37.72 \pm 8.32 \% ; 10-30 \mathrm{mpa}: 9.58 \pm 5.48 \% ; n \geq 18$ mitos from percentage of their total distance in the retrograde direction toward the cut site (retrograde before: $32.85 \pm 8.33 \% ; 10-30$ mpa: before: $0.45 \pm 0.07 \mu \mathrm{m} / \mathrm{s} ; 10-30 \mathrm{mpa}: 0.33 \pm 0.04 \mu \mathrm{m} / \mathrm{s} ; p=0.2633$; retrograde before: $0.31 \pm 0.06 \mu \mathrm{m} / \mathrm{s} ; 10-30 \mathrm{mpa}$ : $0.32 \pm 0.05 \mu \mathrm{m} / \mathrm{s} ; p=0.9170$ ). Scale bar, (in $\boldsymbol{A}, \boldsymbol{B}) 50 \mu \mathrm{m}$.

were elongated in PINK1 morphants (Fig. 7C,D), consistent with the fact that PINK1 promotes mitochondrial fission (Deng et al., 2008; Poole et al., 2008). There was no difference in baseline mitochondrial motility between PINK1 and control morphant embryos (Fig. 7E). Between 2 and 10 min after axotomy, differences in motility between PINK1 and control morphants were not significant $(p=0.12)$. Mitochondrial motility later recovered modestly in PINK1 morphants (Fig. 7F), but this increased motility was not accompanied by axon protection. On the contrary, axon degeneration was slightly accelerated, with a shorter lag phase before fragmentation in PINK1 morphants compared with controls (Fig. 7G). PINK1 knock-down therefore phenocopies the postinjury mitochondrial transport recovery observed in WldS-expressing axons, but does not 

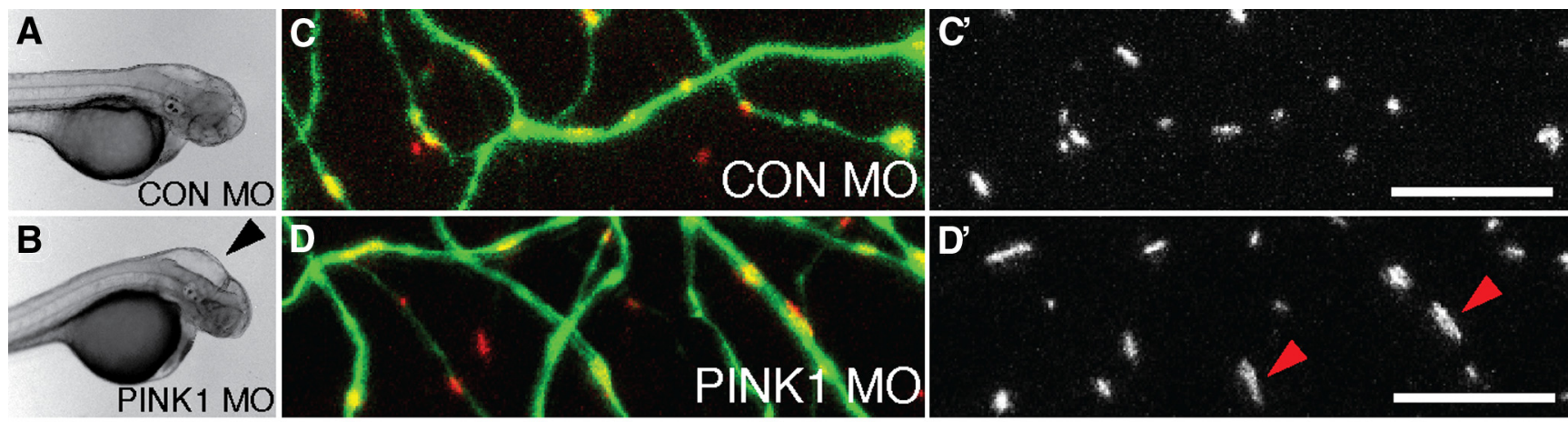

E

Baseline Motility

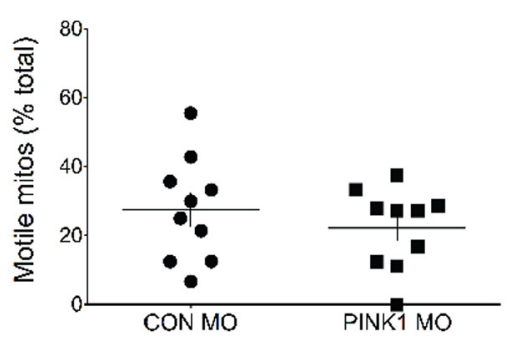

F Mitochondrial Motility

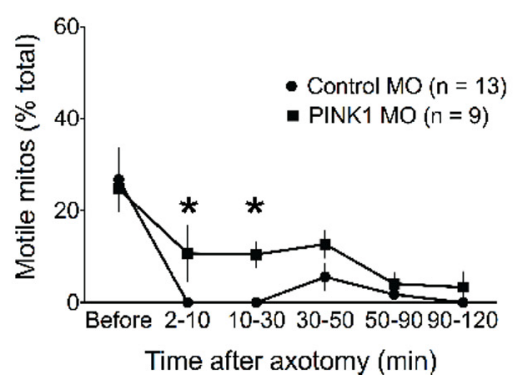

Lag Phase G Before Fragmentation

Figure 7. PINK1 knock-down increases mitochondrial motility after injury and accelerates degeneration. $\boldsymbol{A}, \boldsymbol{B}$, UAS-mitoDsRed embryos were coinjected with control or PINK1 morpholinos and the sensory:Gal4:UAS-GFP transgene used in Figures 1, 2. Phenotypes such as cerebral edema ( $\boldsymbol{B}$, arrowhead) have previously been reported with this PINK1 morpholino. $\boldsymbol{C}-\boldsymbol{D}$, Control (C, $\left.\boldsymbol{C}^{\prime}\right)$ and PINK1 morphants $\left(\boldsymbol{D}, \boldsymbol{D}^{\prime}\right)$ were imaged at $2 \mathrm{dpf}$. Mitochondria were on average longer in PINK1 morphants than controls ( $\boldsymbol{D}$, arrowheads). $\boldsymbol{E}$, There was no difference in baseline mitochondrial motility between PINK1 and control morphant embryos (Control M0: $21.93 \pm \% ;$ PINK1 M0: $26.48 \pm 2.70 \% ; n \geq 5$ axons, $p=0.5285$ ). $\boldsymbol{F}$, Immediately after axotomy, mitochondrial transport was reduced in both groups (WT 2-10 mpa: $0 \pm 0 \%$ motile; PINK1: $8.32 \pm 4.90 \% ; n \geq 9$ axons). Between 10 and 50 mpa, motility was significantly higher in PINK1 morphants than controls (10 -30 mpa: $p=0.028 ; 30-50$ mpa: $p=0.038$ ). $\mathbf{G}$, Axon degeneration after injury was accelerated in PINK1 morphants (quantified as the duration of the lag period between injury and axon fragmentation; Control M0: $135.0 \pm 6.3 \mathrm{~min}$; PINK1 M0: $87.5 \pm 2.5 \mathrm{~min} ; n=8$ axons per group; $p<0.0001)$. Scale bar, $10 \mu \mathrm{m}$.

provide axon protection. Together our results demonstrate that axon motility is neither required nor sufficient for axon protection.

Axonal injury alters the redox state of mitochondria

Because mitochondrial motility per se does not appear to be instructive in WD, we investigated another feature of mitochondrial function. In addition to their roles in ATP synthesis and calcium buffering, mitochondria are the primary site of ROS production in the cell. Because oxidative stress is associated with aging and neurodegeneration (Balaban et al., 2005; Lin and Beal, 2006) and has been proposed to play a role in axon degeneration (Press and Milbrandt, 2008; Fischer and Glass, 2010; Calixto et al., 2012), we determined whether mitochondrial redox state was affected by axotomy, using the ratiometric, redox-sensitive roGFP2 (Hanson et al., 2004) localized to mitochondria (Fig. $8 A$ ). The emission intensity of roGFP2 at two excitation wavelengths ( $\sim 400 \mathrm{~nm}$ and $\sim 475-490 \mathrm{~nm})$ is a function of the redox state of the subcellular compartment to which it is localized: an increase in the 405/488 fluorescence ratio of roGFP2 reflects oxidation (Hanson et al., 2004). We evaluated mito-roGFP2 fluorescence before and after transecting wild-type axons with a laser. Mito-roGFP2 was rapidly and significantly oxidized in the distal axon after injury (2-10 mpa: $161.9 \pm 13.1 \%$ initial) and remained elevated but stable until shortly before fragmentation, when it was further oxidized (Fig. $8 B$ ). In the proximal axon, by contrast, the early increase in oxidation was mild (2-10 mpa: $107.9 \pm 10.5 \%$ initial). Later, mito-roGFP2 oxidation in the proximal axon fell below baseline, and was significantly lower than was observed in the distal axon at all later time points (Fig. 8C).

To determine whether WldS expression might regulate mitochondrial redox state, we examined mito-roGFP2 fluorescence in severed WldS-expressing axons. Unlike the change in wild-type axons, mito-roGFP2 was only mildly and temporarily oxidized after injury in WldS-expressing axons (2-10 mpa: $121.0 \pm 14.6 \%$ initial), and this effect was significantly lower than that seen in wild-type (Fig. $8 B$; $p<0.05$ ). At later time points, mito-roGFP2 oxidation returned to baseline in WldS-expressing axons, and was persistently lower than in wild-type axons (Fig. $8 B, C$; WT 10-50 mpa: $162.4 \pm 10.7 \%$ initial; WldS: $96.0 \pm 8.3 \%$; $p<$ $0.0001)$. We also monitored roGFP2 oxidation in control and PINK1 morphants at $2 \mathrm{dpf}$. PINK1 knock-down did not suppress the redox changes after injury (CON MO 10-50 mpa: $145.5 \pm$ 14.0\%; PINK1 MO: $127.5 \pm 14.5 \%$; $p=0.380)$.

Together, these results demonstrate that injury changes the oxidation state of axonal mitochondria, and the ability to prevent that change correlates with axon protection.

Previous studies have indicated that mitochondria are more depolarized in PINK1 morphants than controls (Anichtchik et al., 2008). To determine whether PINK1 knockdown affected WldS-mediated protection, we expressed WldS in PINK1 and control morphants, and evaluated axonal survival after axotomy. In WldS-expressing control morphants, all axons $(n=10)$ remained intact $24 \mathrm{~h}$ after axotomy. In PINK1 morphants, 1/10 axons degenerated within $12 \mathrm{~h}$ after axotomy. By $24 \mathrm{hpa}$, however, an additional $3 / 10$ had undergone fragmentation. PINK1 knock-down therefore reduces the protective effect of WldS in 
A

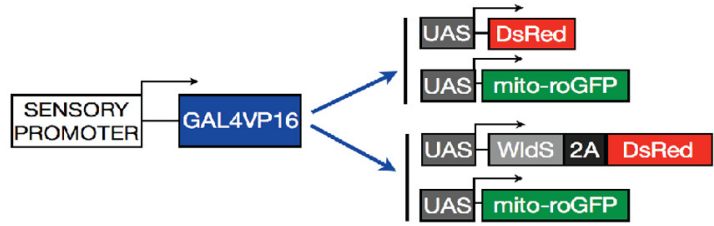

B Mito-roGFP2 Oxidation

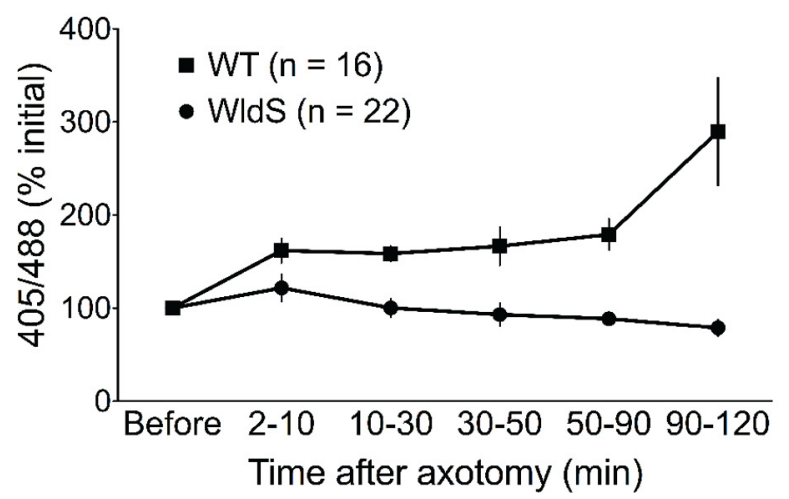

\section{Mito-roGFP2 Oxidation}

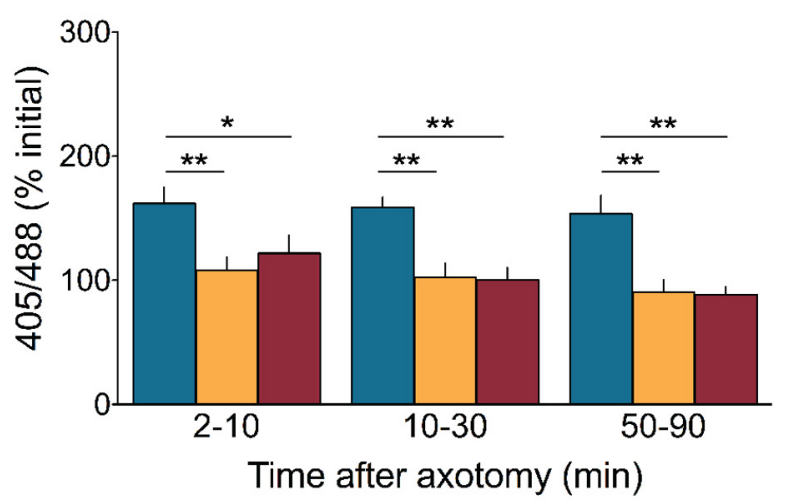

WT distal $(n=16)$

WT proximal $(n=5)$

WldS distal $(n=22)$

Figure 8. Mito-roGFP2 oxidation after injury correlates with axon degeneration. A, Transgenes were generated to express DsRed $+1-$ WIdS in sensory neurons and the redox-sensitive biosensor roGFP2 in the mitochondrial matrix. $\boldsymbol{B}$, Mito-roGFP2 was rapidly oxidized in the distal axon after injury (2-10 mpa: $167.21 \pm 13.91 \%, n=16$ axons), and remained elevated but stable for most of the lag period before fragmentation. Shortly before fragmentation of the distal axon, however, mito-roGFP2 was further oxidized ( $90-120 \mathrm{mpa}: 289.62 \pm 57.79 \% ; n=$ 5 axons). In the distal axon of WIdS-expressing cells, mito-roGFP2 was slightly oxidized acutely after axotomy (2-10 mpa: $121.8 \pm 14.62 \% ; n=22$ axons); however, this effect was still significantly lower than mito-roGFP2 oxidation in wild-type axons ( $p<0.05$, two-way ANOVA with Bonferroni post-tests), and WIdS entirely suppressed the long-term oxidation ( $p<$ 0.001). C, Mito-roGFP2 was not significantly oxidized in the proximal axon any point after axotomy (2-10 mpa: $107.9 \pm 10.49 \%$; 10 -30 mpa: $102.6 \pm 11.13 \%$; 50 -90 mpa: $91.93 \pm$ $12.21 \%$ ). Later in the lag phase, mito-roGFP2 oxidation returned to baseline levels in WIdSexpressing axons, and was significantly lower than was observed in the distal axon at all time points $(p<0.001)$.

transected axons. These results support the hypothesis that mitochondrial function may be relevant to axon protection by WldS.

\section{PGC-1 $\alpha$ delays axon degeneration and roGFP2 oxidation} after injury

The transcriptional coactivator PGC- $1 \alpha$ regulates mitochondrial biogenesis (Wu et al., 1999; Lehman et al., 2000) and ROS detox- ification (St-Pierre et al., 2006). Because mitochondrial redox state correlated with axon degeneration, we tested whether PGC- $1 \alpha$ overexpression could affect WD. We generated reporters to express mouse PGC- $1 \alpha$ and either mitoDsRed or mitoroGFP (Fig. 9A). PGC- $1 \alpha$ expression increased mitochondrial content (Fig. 9B-F): PGC-1 $\alpha$-expressing axons had a greater density of mitochondria (Fig. $9 F$ ), and mitochondria had a dramatically elongated morphology (Fig. 9C,E, G), likely reflecting an increase in mitochondrial biogenesis and/or fusion. PGC- $1 \alpha$ had no effect on baseline mitochondrial transport (WT \% motile: $19.62 \pm 4.82 \%$; PGC-1 $\alpha$ : $22.157 \pm$ $3.82 \% ; n \geq 19$ axons; $p=0.315$ ).

To determine whether PGC- $1 \alpha$ improved axon survival after injury, we axotomized PGC- $1 \alpha$-expressing sensory neurons, which exhibited markedly decreased mito-roGFP2 oxidation after injury compared with wild-type (Fig. 9H). This result suggests that PGC- $1 \alpha$ might help regulate mitochondrial redox homeostasis. PGC- $1 \alpha$ did not prevent acute reduction in mitochondrial transport (percentage motile before: $30.72 \pm 5.80 \%$; 2-10 mpa $16.83 \pm 3.19 \%, p=0.040, n=10$ axons), and motility remained significantly reduced after injury (Fig. 9I). Despite this reduction, however, mitochondrial motility after injury was higher in PGC$1 \alpha$-expressing axons, compared with wild-type axons (Fig. 9I). Like WldS, PGC- $1 \alpha$ therefore mitigated the effects of axonal injury on mitochondrial transport and function. To determine whether these effects correlated with axon protection, we monitored axonal integrity after injury. PGC- $1 \alpha$ delayed the onset of fragmentation relative to wild-type (Fig. 9J). To quantify this correlation, we combined roGFP2 oxidation data from wild-type and PGC- $1 \alpha$-expressing mitochondria at $30 \mathrm{mpa}$, and compared these values to the lag period for each axon (Fig. 9K). Linear regression analysis confirmed that the correlation was significant $\left(R^{2}=0.2855 ; p=0.009\right)$. These results suggest that effects on mitochondrial oxidation state are functionally relevant to axon degeneration and protection.

\section{Discussion}

In vivo imaging of mitochondrial transport and oxidation state after injury

Mitochondrial defects are associated with multiple neurodegenerative disease processes (Sheng and Cai, 2012) but the extent to which different mitochondrial functions contribute to degeneration is unclear. We have described a model that allows mitochondrial transport and physiology to be visualized noninvasively in zebrafish larvae. Like the recently described MitoFish (Plucińska et al., 2012), in which zebrafish mitochondria were labeled with CFP, mitoDsRed expression in zebrafish peripheral sensory neurons permits quantitative analysis of mitochondrial morphology and transport during development and neurodegeneration. We also used mito-roGFP2 (Hanson et al., 2004) to monitor dynamic changes in mitochondrial redox state in a living, vertebrate system. The development and characterization of these and other genetically encoded reporters in zebrafish neurons (Drerup and Nechiporuk, 2013) may provide insight into many biological processes underlying axon degeneration and protection.

\section{Mitochondrial motility can be dissociated from axonal integrity after injury}

Mitochondrial transport defects are associated with many forms of neurodegeneration (Coleman and Perry, 2002), including WD of injured Drosophila axons (Avery et al., 2012). The extent to 
A
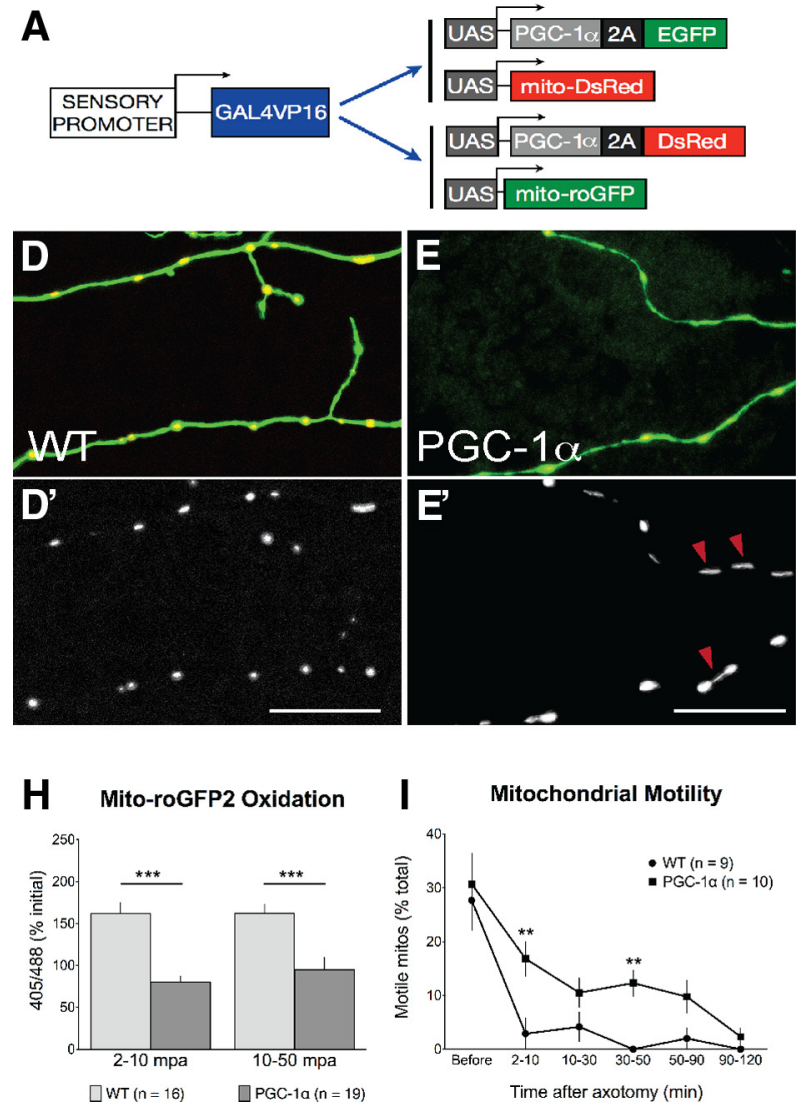
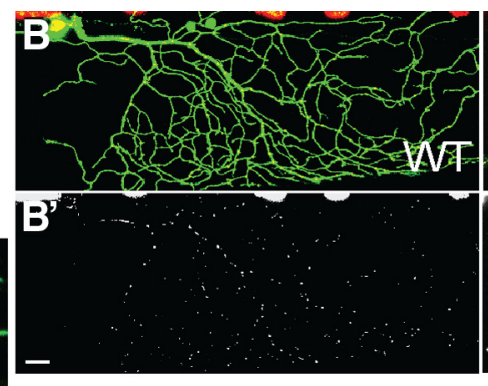

F
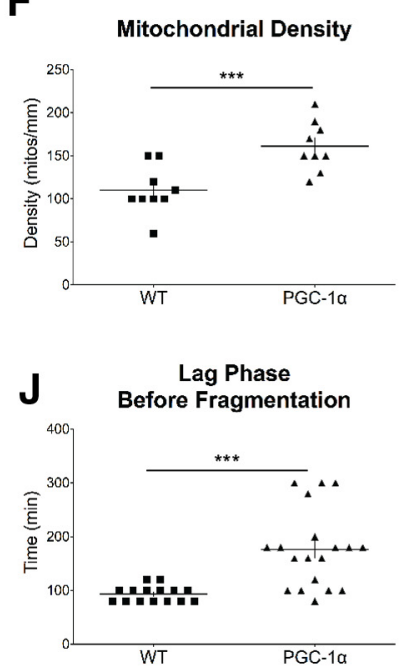

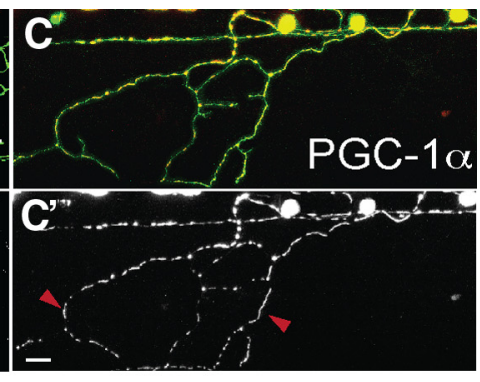

G

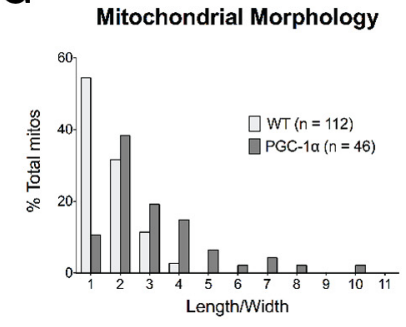

K RogfP2 oxidation vs Lag Period

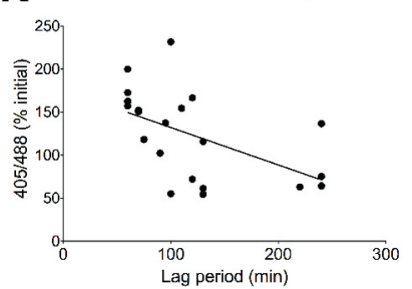

Figure 9. PGC-1 $\alpha$ alters axonal mitochondrial properties and delays degeneration. $\boldsymbol{A}$, Transgenes used to image mitochondria in PGC-1 $\alpha$-expressing neurons. $\boldsymbol{B}-\mathbf{G}, \mathrm{Mouse}$ PGC-1 $\alpha$ expression in zebrafish sensory neurons caused a significant increase in mitochondrial content, quantified as a higher density of stationary mitochondria $(\boldsymbol{F} ; \mathrm{WT}: 110 \pm 9.0$ mitos/mm; PGC- $1 \alpha$ : $161 \pm 10.3$ mitos/mm; $n \geq 9$ axons) and an elongated mitochondrial phenotype ( $\boldsymbol{C}, \boldsymbol{E}, \boldsymbol{G}$; arrowheads in $\boldsymbol{C}^{\prime}$ and $\boldsymbol{E}^{\prime}$ point to elongated mitochondria). $\boldsymbol{H}$, PGC- $1 \alpha$-expressing axons exhibited significantly less roGFP2 oxidation compared with wild-type immediately after axotomy (WT 2-10 mpa: $161.9 \pm 13.14 \%$ initial; PGC $-1: 79.98 \pm 7.27 \% n \geq 11$ axons; $p<0.001$ ) and later in the lag period (WT 10 -50 mpa: $162.4 \pm 10.65 \%$ initial; PGC-1 $\alpha$ : $94.74 \pm 14.99 \%$ initial; $n \geq 19$ axons; $p=0.005)$. $I$, Quantification of mitochondrial transport after axotomy of PGC-1 $\alpha$-expressing axons. Mitochondrial transport was acutely and persistently reduced after axotomy in PGC1 $\alpha$-expressing cells (motility before: $30.72 \pm 5.80 \% ; 2-10 \mathrm{mpa}: 16.83 \pm 3.19 \% ; 10-30 \mathrm{mpa}$ : $10.52 \pm 2.70 \%$; $30-50$ mpa: $12.30 \pm 2.43 \% ; 50-90$ mpa: $9.77 \pm 3.06 \% ; 90-120 \mathrm{mpa}: 2.32 \pm 1.60 \% ; n \geq 9$ axons; $p<0.001)$. However, motility after injury was significantly higher than in wild-type axons at $2-10 \mathrm{mpa}(p=0.0069)$. This trend persisted throughout most of the lag period, though it was not always statistically significant $(10-30 \mathrm{mpa}, p=0.1485 ; 30-50 \mathrm{mpa}, p=0.0020 ; 50-90 \mathrm{mpa}$, $p=0.1751$ ). Asterisks represent significance compared with wild-type. $J$, Changes in mitochondrial transport and function correlated with a delay in axon degeneration, with a longer lag period before fragmentation in injured PGC-1 $\alpha$-expressing axons (WT: $94.6 \pm 4.7 \mathrm{~min} ; \mathrm{PGC1} \alpha$ : $176.8 \pm 16.6 \mathrm{~min} ; n \geq 15$ axons; $p<0.0001$ ). $\boldsymbol{K}$, Mitochondrial roGFP oxidation data from wild-type and PGC-1 $\alpha$-expressing axons at time points between 10 and $30 \mathrm{~min}$ after injury were pooled. Linear regression analysis revealed a negative correlation between roGFP2 oxidation and the lag period before degeneration $\left(R^{2}=0.2855 ; p=23\right.$ axons; $\left.p=0.009\right)$. Scale bars: $\boldsymbol{B}, \boldsymbol{C}, 50 \mu \mathrm{m} ; \boldsymbol{D}, \boldsymbol{E}, 20 \mu \mathrm{m}$.

which such defects are instructive in degeneration, however, is unclear. Mitochondrial, but not vesicular, transport terminated in zebrafish peripheral sensory neurons after injury. Transport in the proximal axon persisted, though transport behaviors shifted to favor retention of mitochondria at the injury site. Because the proximal axon does not degenerate, this correlation raised the possibility that mitochondrial arrest might underlie axon degeneration. Further experiments, however, dissociated mitochondrial transport from axon degeneration. In contrast to recent findings in flies (Avery et al., 2012), we detected no difference in overall mitochondrial motility in uninjured cells expressing the axon-protective protein WldS. Moreover, transport arrest was observed both acutely and several hours after injury in WldSexpressing axons. This result confirmed that, as was recently observed in a neurodegenerative disease model system (Marinkovic et al., 2012), long-term mitochondrial transport is not required for axon survival, and revealed that long-term mitochondrial transport preservation does not mediate the protective effect of WldS.

\section{Phases of mitochondrial transport arrest}

A more detailed analysis of mitochondrial transport in wildtype and WldS-expressing axons allowed us to distinguish different phases within the lag period, and revealed a transient effect of WldS on mitochondrial transport. The first phase occurred immediately after injury and was not suppressed by WldS. This acute arrest was limited to the region adjacent to the injury site, and may be mediated by rapid calcium influx (Yawo and Kuno, 1985; Ziv and Spira, 1995; Adalbert et al., 2012; Avery et al., 2012). Calcium-induced mitochondrial transport arrest is an adaptive response promoting local calcium buffering and ATP synthesis at sites of high demand (Saotome et al., 2008; Macaskill et al., 2009; Wang and Schwarz, 2009) and may minimize acute damage. PGC- $1 \alpha-$ expressing cells also exhibited reduced transport after injury, though to a lesser degree than in wild-type axons. Because PGC- $1 \alpha$ increases mitochondrial density, it is possible that sufficient calcium buffering is provided by the same number, but a smaller percentage, of mitochondria. 
Observation of mitochondria later in the lag phase revealed a temporary recovery of transport in WldS-expressing axons. This recovery did not occur in wild-type axons, suggesting that it might be relevant to axon protection. Mitochondrial distribution, which is relevant in another disease model (Misko et al., 2012), was not affected by WldS expression at baseline or after injury. It is therefore unlikely that early transport recovery provided long-term protection by regulating mitochondrial spacing. The early effects of WldS on transport may confer protection by promoting a more robust network of mitochondria. Indeed, transport behaviors in this recovery phase favored mitochondrial retention at the cut site, mirroring mitochondrial motility in the proximal axon after injury. These transport behaviors may provide a selective benefit, providing local calcium buffering and energy production that support the entire mitochondrial network. By contrast, PINK1-deficient mitochondria, which are more depolarized (Anichtchik et al., 2008) and more vulnerable to oxidative stress (Wang et al., 2006; Mai et al., 2010) than controls, also exhibit a moderate recovery of transport after injury. However, axons in PINK1 morphants degenerate more rapidly than in control morphants. The mitochondrial transport recovery in PINK1 morphants is therefore not equivalent to that observed in WldS-expressing axons. This may reflect a functional difference between mitochondria in PINK1-deficient and WldSexpressing axons, either at baseline or after injury.

\section{Dynamic changes in mitochondrial redox state after injury}

Mitochondrial transport eventually terminated throughout the distal axon in WldS-expressing cells, and did not recover. Mitochondria were immobile $24 \mathrm{~h}$ after injury despite persistence of the distal axon. This finding does not preclude the possibility that the early and transient recovery of mitochondrial transport provides long-term effects, but suggests that other aspects of mitochondrial function may be more critical at later stages. To determine whether ROS production might be relevant to axon degeneration and protection, we evaluated mitochondrial redox state before and after axotomy using the redox-sensitive biosensor mito-roGFP2 (Hanson et al., 2004). After axotomy, mitoroGFP2 was rapidly oxidized in the disconnected axon branch, consistent with increased ROS production in the mitochondrial matrix. This effect was also observed in the distal axons of control and PINK1 morphants, but not in wild-type proximal axons (still attached to the cell body) or in WldS-expressing axons. Because mitochondrial ROS production can be induced by calcium (Yan et al., 2006), increased calcium buffering by WldS-expressing mitochondria (Avery et al., 2012) could contribute to this difference. It is also possible that WldS directly affects mitochondrial ROS production. Consistent with this possibility, overexpression of Nmnat (the critical catalytic component of the WldS fusion protein) prevents degeneration of cultured neurons exposed to hydrogen peroxide (Press and Milbrandt, 2008). Moreover, antioxidant treatment protects against Wallerian-like degeneration in Caenorhabditis elegans and mice (Calixto et al., 2012).

Oxidation of roGFP2 remained elevated but stable in wildtype distal axons for most of the lag phase. Shortly before axon fragmentation, however, mito-roGFP2 oxidation rose further. This increase, which was not observed in WldS-expressing axons, may reflect formation of the mPTP, which occurs under conditions of calcium overload (Haworth and Hunter, 1979; Hunter and Haworth, 1979a,b), particularly in the presence of ROS (Kowaltowski et al., 1996; Vercesi et al., 1997). The permeability transition results in further ROS production (Hansson et al., 2008), loss of membrane potential, and calcium efflux into the cytoplasm, where it activates calcium-dependent cysteine proteases that degrade the cytoskeleton (George et al., 1995).

\section{PGC-1 $\alpha$ expression delays mito-roGFP2 oxidation and axon degeneration}

The transcriptional coactivator PGC- $1 \alpha$ has many targets that regulate mitochondrial biogenesis, bioenergetics, and ROS detoxification (Wu et al., 1999; Lehman et al., 2000; St-Pierre et al., 2006; Cantó and Auwerx, 2009). Impairments in PGC- $1 \alpha$ mediated transcription have been associated with Huntington disease and Parkinson disease, and PGC- $1 \alpha$ has been proposed as a therapeutic target (Cui et al., 2006; Weydt et al., 2006; Zheng et al., 2010; Shin et al., 2011; Tsunemi and La Spada, 2012). PGC-1 $\alpha$ expression delayed axon degeneration of zebrafish sensory neurons after transection. Because the distal axon is not connected to the cell body after axotomy, injury-induced transcriptional activation by PGC- $1 \alpha$ cannot contribute to this protection. However, PGC- $1 \alpha$ increased mitochondrial density, and a larger number of mitochondria may be able to buffer more calcium. Additionally, PGC- $1 \alpha$ may upregulate ROS detoxification programs at baseline, making mitochondria resistant to ROS buildup after injury. Indeed, PGC- $1 \alpha$ overexpression protects cultured neurons from ROS-mediated degeneration, an effect associated with increased mRNA expression of multiple enzymes involved in ROS detoxification (St-Pierre et al., 2006). Nevertheless, detachment from the cell body prevents the distal axon from enjoying further effects of PGC- $1 \alpha$ activation after injury. This limitation could explain why the delay of WD in PGC- $1 \alpha$ expressing axons, although significant, was not comparable to that provided by WldS expression. In many neurodegenerative disease models, axon degeneration proceeds via a WD-like mechanism without physical separation from the cell body. PGC- $1 \alpha$ overexpression may provide improved protection in these models, as axons could still benefit from upregulation of protective gene expression after the initial insult.

\section{References}

Adalbert R, Morreale G, Paizs M, Conforti L, Walker SA, Roderick HL, Bootman MD, Siklós L, Coleman MP (2012) Intra-axonal calcium changes after axotomy in wild-type and slow Wallerian degeneration axons. Neuroscience 225:44-54. CrossRef Medline

Anichtchik O, Diekmann H, Fleming A, Roach A, Goldsmith P, Rubinsztein DC (2008) Loss of PINK1 function affects development and results in neurodegeneration in zebrafish. J Neurosci 28:8199-8207. CrossRef Medline

Avery MA, Rooney TM, Pandya JD, Wishart TM, Gillingwater TH, Geddes JW, Sullivan PG, Freeman MR (2012) WldS prevents axon degeneration through increased mitochondrial flux and enhanced mitochondrial $\mathrm{Ca}^{2+}$ buffering. Curr Biol 22:596-600. CrossRef Medline

Balaban RS, Nemoto S, Finkel T (2005) Mitochondria, oxidants, and aging. Cell 120:483-495. CrossRef Medline

Barrientos SA, Martinez NW, Yoo S, Jara JS, Zamorano S, Hetz C, Twiss JL, Alvarez J, Court FA (2011) Axonal degeneration is mediated by the mitochondrial permeability transition pore. J Neurosci 31:966-978. CrossRef Medline

Calixto A, Jara JS, Court FA (2012) Diapause formation and downregulation of insulin-like signaling via DAF-16/FOXO delays axonal degeneration and neuronal loss. PLoS Genet 8:e1003141. CrossRef Medline

Cantó C, Auwerx J (2009) PGC-1alpha, SIRT1 and AMPK, an energy sensing network that controls energy expenditure. Curr Opin Lipidol 20:98105. CrossRef Medline

Coleman M (2005) Axon degeneration mechanisms: commonality amid diversity. Nat Rev Neurosci 6:889-898. CrossRef Medline

Coleman MP, Perry VH (2002) Axon pathology in neurological disease: a neglected therapeutic target. Trends Neurosci 25:532-537. CrossRef Medline

Coleman MP, Conforti L, Buckmaster EA, Tarlton A, Ewing RM, Brown MC, 
Lyon MF, Perry VH (1998) An 85-kb tandem triplication in the slow Wallerian degeneration (Wlds) mouse. Proc Natl Acad Sci U S A 95: 9985-9990. CrossRef Medline

Court FA, Coleman MP (2012) Mitochondria as a central sensor for axonal degenerative stimuli. Trends Neurosci 35:364-372. CrossRef Medline

Cui L, Jeong H, Borovecki F, Parkhurst CN, Tanese N, Krainc D (2006) Transcriptional repression of PGC-1alpha by mutant huntingtin leads to mitochondrial dysfunction and neurodegeneration. Cell 127:59-69. CrossRef Medline

Deng H, Dodson MW, Huang H, Guo M (2008) The Parkinson's disease genes pink1 and parkin promote mitochondrial fission and/or inhibit fusion in Drosophila. Proc Natl Acad Sci U S A 105:14503-14508. CrossRef Medline

Donnelly ML, Luke G, Mehrotra A, Li X, Hughes LE, Gani D, Ryan MD (2001) Analysis of the aphthovirus 2A/2B polyprotein "cleavage" mechanism indicates not a proteolytic reaction, but a novel translational effect: a putative ribosomal "skip." J Gen Virol 82:1013-1025. Medline

Drerup CM, Nechiporuk AV (2013) JNK-interacting protein 3 mediates the retrograde transport of activated c-jun $\mathrm{N}$-terminal kinase and lysosomes. PLoS Genet 9:e1003303. CrossRef Medline

Fang Y, Soares L, Teng X, Geary M, Bonini NM (2012) A novel Drosophila model of nerve injury reveals an essential role of Nmnat in maintaining axonal integrity. Curr Biol 22:590-595. CrossRef Medline

Fischer LR, Glass JD (2010) Oxidative stress induced by loss of $\mathrm{Cu}, \mathrm{Zn}$ superoxide dismutase (SOD1) or superoxide-generating herbicides causes axonal degeneration in mouse DRG cultures. Acta Neuropathol 119:249-259. CrossRef Medline

George EB, Glass JD, Griffin JW (1995) Axotomy-induced axonal degeneration is mediated by calcium influx through ion-specific channels. J Neurosci 15:6445-6452. Medline

Hanai J, Cao P, Tanksale P, Imamura S, Koshimizu E, Zhao J, Kishi S, Yamashita M, Phillips PS, Sukhatme VP, Lecker SH (2007) The musclespecific ubiquitin ligase atrogin-1/MAFbx mediates statin-induced muscle toxicity. J Clin Invest 117:3940-3951. CrossRef Medline

Hanson GT, Aggeler R, Oglesbee D, Cannon M, Capaldi RA, Tsien RY, Remington SJ (2004) Investigating mitochondrial redox potential with redox-sensitive green fluorescent protein indicators. J Biol Chem 279: 13044-13053. CrossRef Medline

Hansson MJ, Månsson R, Morota S, Uchino H, Kallur T, Sumi T, Ishii N, Shimazu M, Keep MF, Jegorov A, Elmér E (2008) Calcium-induced generation of reactive oxygen species in brain mitochondria is mediated by permeability transition. Free Radic Biol Med 45:284-294. CrossRef Medline

Haworth RA, Hunter DR (1979) The $\mathrm{Ca}^{2+}$-induced membrane transition in mitochondria: II. Nature of the $\mathrm{Ca}^{2+}$ trigger site. Arch Biochem Biophys 195:460-467. CrossRef Medline

Higashijima S, Hotta Y, Okamoto H (2000) Visualization of cranial motor neurons in live transgenic zebrafish expressing green fluorescent protein under the control of the islet-1 promoter/enhancer. J Neurosci 20:206218. Medline

Hunter DR, Haworth RA (1979a) The $\mathrm{Ca}^{2+}$-induced membrane transition in mitochondria: I. The protective mechanisms. Arch Biochem Biophys 195:453-459. CrossRef Medline

Hunter DR, Haworth RA (1979b) The $\mathrm{Ca}^{2+}$-induced membrane transition in mitochondria: III. Transitional $\mathrm{Ca}^{2+}$ release. Arch Biochem Biophys 195:468-477. CrossRef Medline

Kawakami K (2004) Transgenesis and gene trap methods in zebrafish by using the Tol2 transposable element. Methods Cell Biol 77:201-222. CrossRef Medline

Kitay BM, McCormack R, Wang Y, Tsoulfas P, Zhai RG (2013) Mislocalization of neuronal mitochondria reveals regulation of Wallerian degeneration and NMNAT/WLDS-mediated axon protection independent of axonal mitochondria. Hum Mol Genet 22:1601-1614. CrossRef Medline

Köster RW, Fraser SE (2001) Tracing transgene expression in living zebrafish embryos. Dev Biol 233:329-346. CrossRef Medline

Kowaltowski AJ, Castilho RF, Vercesi AE (1996) Opening of the mitochondrial permeability transition pore by uncoupling or inorganic phosphate in the presence of $\mathrm{Ca}^{2+}$ is dependent on mitochondrial-generated reactive oxygen species. FEBS Lett 378:150-152. CrossRef Medline

Kwan KM, Fujimoto E, Grabher C, Mangum BD, Hardy ME, Campbell DS, Parant JM, Yost HJ, Kanki JP, Chien CB (2007) The Tol2kit: a multisite gateway-based construction kit for Tol2 transposon transgenesis constructs. Dev Dyn 236:3088-3099. CrossRef Medline

Lehman JJ, Barger PM, Kovacs A, Saffitz JE, Medeiros DM, Kelly DP (2000) Peroxisome proliferator-activated receptor gamma coactivator-1 promotes cardiac mitochondrial biogenesis. J Clin Invest 106:847-856. CrossRef Medline

Lin MT, Beal MF (2006) Mitochondrial dysfunction and oxidative stress in neurodegenerative diseases. Nature 443:787-795. CrossRef Medline

Lister JA, Robertson CP, Lepage T, Johnson SL, Raible DW (1999) nacre encodes a zebrafish microphthalmia-related protein that regulates neural-crest-derived pigment cell fate. Development 126:3757-3767. Medline

Liu S, Sawada T, Lee S, Yu W, Silverio G, Alapatt P, Millan I, Shen A, Saxton W, Kanao T, Takahashi R, Hattori N, Imai Y, Lu B (2012) Parkinson's disease-associated kinase PINK1 regulates Miro protein level and axonal transport of mitochondria. PLoS Genet 8:e1002537. CrossRef Medline

Macaskill AF, Rinholm JE, Twelvetrees AE, Arancibia-Carcamo IL, Muir J, Fransson A, Aspenstrom P, Attwell D, Kittler JT (2009) Mirol is a calcium sensor for glutamate receptor-dependent localization of mitochondria at synapses. Neuron 61:541-555. CrossRef Medline

Mack TG, Reiner M, Beirowski B, Mi W, Emanuelli M, Wagner D, Thomson D, Gillingwater T, Court F, Conforti L, Fernando FS, Tarlton A, Andressen C, Addicks K, Magni G, Ribchester RR, Perry VH, Coleman MP (2001) Wallerian degeneration of injured axons and synapses is delayed by a Ube4b/Nmnat chimeric gene. Nat Neurosci 4:1199-1206. CrossRef Medline

Mai S, Klinkenberg M, Auburger G, Bereiter-Hahn J, Jendrach M (2010) Decreased expression of Drp1 and Fis1 mediates mitochondrial elongation in senescent cells and enhances resistance to oxidative stress through PINK1. J Cell Sci 123:917-926. CrossRef Medline

Marinkovic P, Reuter MS, Brill MS, Godinho L, Kerschensteiner M, Misgeld $\mathrm{T}$ (2012) Axonal transport deficits and degeneration can evolve independently in mouse models of amyotrophic lateral sclerosis. Proc Natl Acad Sci U S A 109:4296-4301. CrossRef Medline

Martin SM, O’Brien GS, Portera-Cailliau C, Sagasti A (2010) Wallerian degeneration of zebrafish trigeminal axons in the skin is required for regeneration and developmental pruning. Development 137:3985-3994. CrossRef Medline

Matsuda N, Sato S, Shiba K, Okatsu K, Saisho K, Gautier CA, Sou YS, Saiki S, Kawajiri S, Sato F, Kimura M, Komatsu M, Hattori N, Tanaka K (2010) PINK1 stabilized by mitochondrial depolarization recruits Parkin to damaged mitochondria and activates latent Parkin for mitophagy. J Cell Biol 189:211-221. CrossRef Medline

Meyer MP, Smith SJ (2006) Evidence from in vivo imaging that synaptogenesis guides the growth and branching of axonal arbors by two distinct mechanisms. J Neurosci 26:3604-3614. CrossRef Medline

Misgeld T, Kerschensteiner M, Bareyre FM, Burgess RW, Lichtman JW (2007) Imaging axonal transport of mitochondria in vivo. Nat Methods 4:559-561. CrossRef Medline

Misko AL, Sasaki Y, Tuck E, Milbrandt J, Baloh RH (2012) Mitofusin2 mutations disrupt axonal mitochondrial positioning and promote axon degeneration. J Neurosci 32:4145-4155. CrossRef Medline

O’Brien GS, Martin SM, Söllner C, Wright GJ, Becker CG, Portera-Cailliau C, Sagasti A (2009a) Developmentally regulated impediments to skin reinnervation by injured peripheral sensory axon terminals. Curr Biol 19: 2086-2090. CrossRef Medline

O’Brien GS, Rieger S, Martin SM, Cavanaugh AM, Portera-Cailliau C, Sagasti A (2009b) Two-photon axotomy and time-lapse confocal imaging in live zebrafish embryos. J Vis Exp 24:1129. CrossRef Medline

Palanca AM, Lee SL, Yee LE, Joe-Wong C, Trinh le A, Hiroyasu E, Husain M, Fraser SE, Pellegrini M, Sagasti A (2013) New transgenic reporters identify somatosensory neuron subtypes in larval zebrafish. Dev Neurobiol 73:152-167. CrossRef Medline

Perry VH, Brown MC, Lunn ER (1991) VERY slow retrograde and Wallerian degeneration in the CNS of C57BL/OLA mice. Eur J Neurosci 3:102105. CrossRef Medline

Plucińska G, Paquet D, Hruscha A, Godinho L, Haass C, Schmid B, Misgeld T (2012) In vivo imaging of disease-related mitochondrial dynamics in a vertebrate model system. J Neurosci 32:16203-16212. CrossRef Medline

Poole AC, Thomas RE, Andrews LA, McBride HM, Whitworth AJ, Pallanck LJ (2008) The PINK1/Parkin pathway regulates mitochondrial morphology. Proc Natl Acad Sci U S A 105:1638-1643. CrossRef Medline 
Press C, Milbrandt J (2008) Nmnat delays axonal degeneration caused by mitochondrial and oxidative stress. J Neurosci 28:4861-4871. CrossRef Medline

Sagasti A, Guido MR, Raible DW, Schier AF (2005) Repulsive interactions shape the morphologies and functional arrangement of zebrafish peripheral sensory arbors. Curr Biol 15:804-814. CrossRef Medline

Saotome M, Safiulina D, Szabadkai G, Das S, Fransson A, Aspenstrom P, Rizzuto R, Hajnóczky G (2008) Bidirectional $\mathrm{Ca}^{2+}$-dependent control of mitochondrial dynamics by the Miro GTPase. Proc Natl Acad Sci U S A 105:20728-20733. CrossRef Medline

Sheng ZH, Cai Q (2012) Mitochondrial transport in neurons: impact on synaptic homeostasis and neurodegeneration. Nat Rev Neurosci 13: 77-93. CrossRef Medline

Shin JH, Ko HS, Kang H, Lee Y, Lee YI, Pletinkova O, Troconso JC, Dawson VL, Dawson TM (2011) PARIS (ZNF746) repression of PGC- $1 \alpha$ contributes to neurodegeneration in Parkinson's disease. Cell 144:689-702. CrossRef Medline

St-Pierre J, Drori S, Uldry M, Silvaggi JM, Rhee J, Jäger S, Handschin C, Zheng K, Lin J, Yang W, Simon DK, Bachoo R, Spiegelman BM (2006) Suppression of reactive oxygen species and neurodegeneration by the PGC-1 transcriptional coactivators. Cell 127:397-408. CrossRef Medline

Tang W, Ehrlich I, Wolff SB, Michalski AM, Wölfl S, Hasan MT, Lüthi A, Sprengel R (2009) Faithful expression of multiple proteins via 2Apeptide self-processing: a versatile and reliable method for manipulating brain circuits. J Neurosci 29:8621-8629. CrossRef Medline

Tsunemi T, La Spada AR (2012) PGC- $1 \alpha$ at the intersection of bioenergetics regulation and neuron function: from Huntington's disease to Parkinson's disease and beyond. Prog Neurobiol 97:142-151. CrossRef Medline

Uemura O, Okada Y, Ando H, Guedj M, Higashijima S, Shimazaki T, Chino $\mathrm{N}$, Okano H, Okamoto H (2005) Comparative functional genomics revealed conservation and diversification of three enhancers of the isll gene for motor and sensory neuron-specific expression. Dev Biol 278:587-606. CrossRef Medline

Vercesi AE, Kowaltowski AJ, Grijalba MT, Meinicke AR, Castilho RF (1997)
The role of reactive oxygen species in mitochondrial permeability transition. Biosci Rep 17:43-52. CrossRef Medline

Wang D, Qian L, Xiong H, Liu J, Neckameyer WS, Oldham S, Xia K, Wang J, Bodmer R, Zhang Z (2006) Antioxidants protect PINK1-dependent dopaminergic neurons in Drosophila. Proc Natl Acad Sci U S A 103:1352013525. CrossRef Medline

Wang X, Schwarz TL (2009) The mechanism of $\mathrm{Ca}^{2+}$-dependent regulation of kinesin-mediated mitochondrial motility. Cell 136:163-174. CrossRef Medline

Weydt P, Pineda VV, Torrence AE, Libby RT, Satterfield TF, Lazarowski ER, Gilbert ML, Morton GJ, Bammler TK, Strand AD, Cui L, Beyer RP, Easley CN, Smith AC, Krainc D, Luquet S, Sweet IR, Schwartz MW, La Spada AR (2006) Thermoregulatory and metabolic defects in Huntington's disease transgenic mice implicate PGC-1alpha in Huntington's disease neurodegeneration. Cell Metab 4:349-362. CrossRef Medline

Wu Z, Puigserver P, Andersson U, Zhang C, Adelmant G, Mootha V, Troy A, Cinti S, Lowell B, Scarpulla RC, Spiegelman BM (1999) Mechanisms controlling mitochondrial biogenesis and respiration through the thermogenic coactivator PGC-1. Cell 98:115-124. CrossRef Medline

Yahata N, Yuasa S, Araki T (2009) Nicotinamide mononucleotide adenylyltransferase expression in mitochondrial matrix delays Wallerian degeneration. J Neurosci 29:6276-6284. CrossRef Medline

Yan Y, Wei CL, Zhang WR, Cheng HP, Liu J (2006) Cross-talk between calcium and reactive oxygen species signaling. Acta Pharmacol Sin 27: 821-826. CrossRef Medline

Yawo H, Kuno M (1985) Calcium dependence of membrane sealing at the cut end of the cockroach giant axon. J Neurosci 5:1626-1632. Medline

Zheng B, et al. (2010) PGC-1 $\alpha$, a potential therapeutic target for early intervention in Parkinson's disease. Sci Transl Med 2:52ra73. CrossRef Medline

Ziv NE, Spira ME (1995) Axotomy induces a transient and localized elevation of the free intracellular calcium concentration to the millimolar range. J Neurophysiol 74:2625-2637. Medline 